\title{
Analyses of coal extraction and spoil handling techniques in mountainous areas
}

\author{
Shiva Prasad B. Kolli \\ West Virginia University
}

Follow this and additional works at: https://researchrepository.wvu.edu/etd

\footnotetext{
Recommended Citation

Kolli, Shiva Prasad B., "Analyses of coal extraction and spoil handling techniques in mountainous areas" (2001). Graduate Theses, Dissertations, and Problem Reports. 1120.

https://researchrepository.wvu.edu/etd/1120

This Thesis is protected by copyright and/or related rights. It has been brought to you by the The Research Repository @ WVU with permission from the rights-holder(s). You are free to use this Thesis in any way that is permitted by the copyright and related rights legislation that applies to your use. For other uses you must obtain permission from the rights-holder(s) directly, unless additional rights are indicated by a Creative Commons license in the record and/ or on the work itself. This Thesis has been accepted for inclusion in WVU Graduate Theses, Dissertations, and Problem Reports collection by an authorized administrator of The Research Repository @ WVU. For more information, please contact researchrepository@mail.wvu.edu.
} 


\title{
Analyses of Coal Extraction and Spoil Handling Techniques in Mountainous Areas
}

Shiva Prasad B. Kolli

\author{
Thesis \\ Submitted to the \\ College of Engineering and Mineral Resources \\ At West Virginia University \\ In Partial Fulfillment of the Requirements for the Degree of
}

\author{
Master of Science \\ In \\ Mining Engineering
}
A. W. Khair, Ph.D., Committee Chair
Syd S. Peng, Ph.D.
Yi Luo, Ph.D.
Morgantown, West Virginia
2001

Keywords: Mountaintop Removal Mining (MTR), Valley Fill, Slope Stability, Probability Analysis, and Monte Carlo Simulation 


\begin{abstract}
Analyses of Coal Extraction and Spoil Handling Techniques in Mountainous Areas
\end{abstract}

\author{
Shiva Prasad B. Kolli
}

Surface mining of multiple seams by mountaintop mining methodology is complex in the Appalachian region of West Virginia. Mining operations in these mountainous areas can be considered as customized forms of surface mining techniques. The customization of the mining methods is greatly dominated by the location, geology, and stratigraphic succession of coal seams in the area.

Owing to its unique mining operations, and the environmental effects associated with it, mountaintop removal method of mining has become an issue of public concern. The pertinence of the present mountaintop mining operations and reclamation techniques, with respect to being in compliance with Surface Mining Control and Reclamation Act of 1977 (SMCRA), as well as both Federal and State regulations is at question.

The ability of mining engineers to accurately analyze mountaintop-mining operations is compromised by a variety of factors. These may be broadly classified as theoretical and practical considerations. The net result of these considerations is that the exact analysis of the entire mining operation cannot be made. Hence, two major activities of mountaintop operations 1. Coal Extraction, and 2. Valley fill slope stability are analyzed.

The objective of this research is to analyze the pertinent coal extraction methods, and to study the slope stability of valley fill slopes using deterministic as well as probabilistic approach. 


\section{Acknowledgements}

This thesis is made possible due to the kindness and guided help of many individuals. First, I would like to express my gratitude to my advisor Dr. A. W. Khair, for his guidance, support, and inspiration towards the completion of this research. His willingness to oversee this endeavor, time, and dedication to making me a more technical writer was greatly appreciated. Thanks are due to my defense committee, Dr. Syd S. Peng and Dr. Yi Luo for their constructive comments and review of this document.

Special thanks to Mr. Fernand A, Barata, P. E., for providing information and insight in mountaintop mining. Thanks to Dr. Thomas F. Torries for making me understand the principles of Risk evaluation.

Thanks to Coal and Energy Research Bureau (CERB) of the State of West Virginia for sponsoring this project. Sincere thanks to all the other people named and not named who have helped me with the project.

Finally, thanks to the staff at National Alternative Fuels Training Consortium (NAFTC) for their tremendous support throughout my graduate studies. 


\section{Table of Contents}

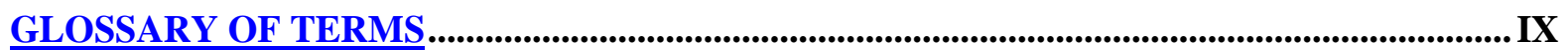

CHAPTER 1 INTRODUCTION

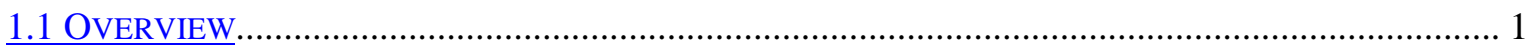

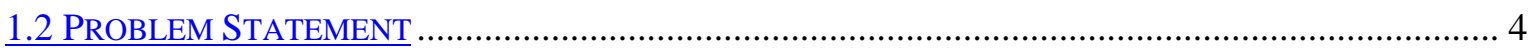

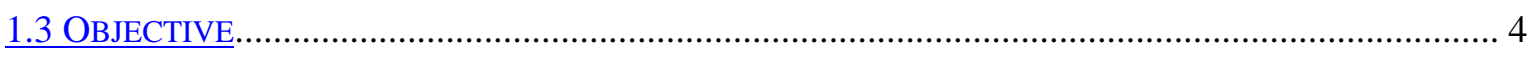

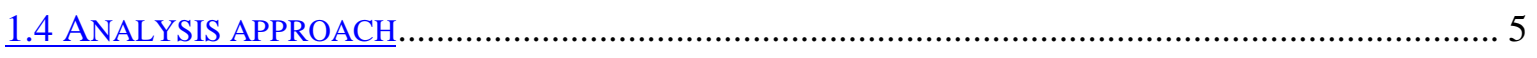

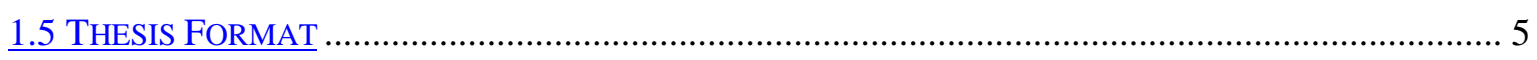

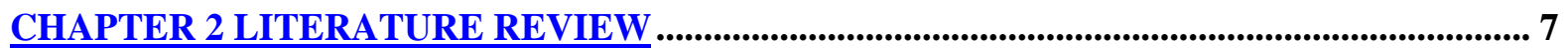

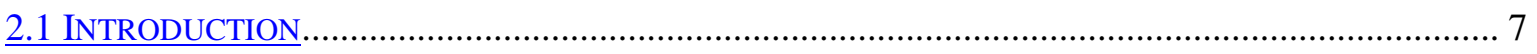

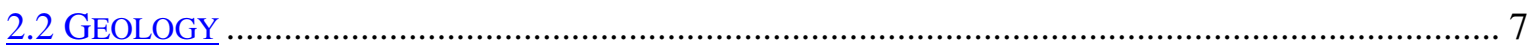

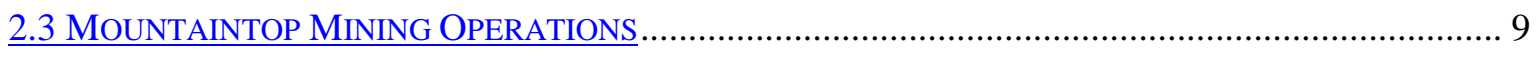

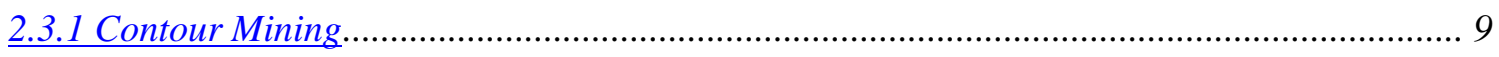

2.3.2 Mountaintop removal (MTR) mining ........................................................................... 9

2.4 GOVERNING REGULATIONS AND AOC MODEL ................................................................. 10

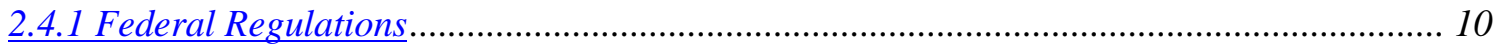

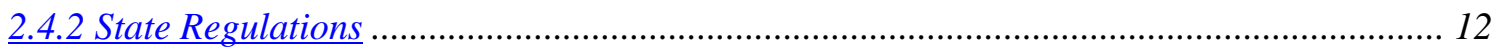

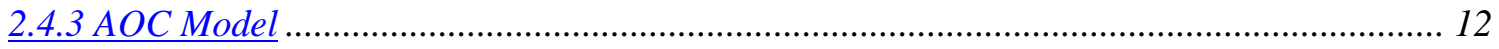

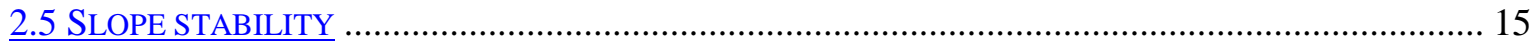

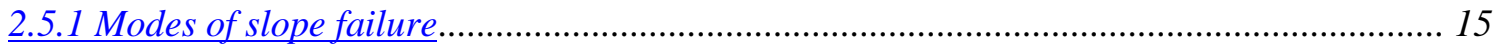

2.5.2 Traditional Slope Stability Analysis Methods .................................................................. 15

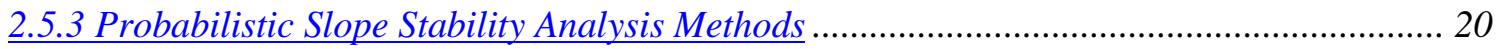

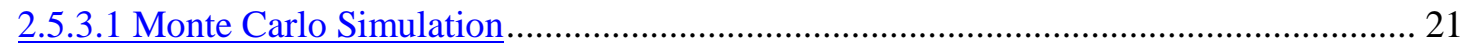

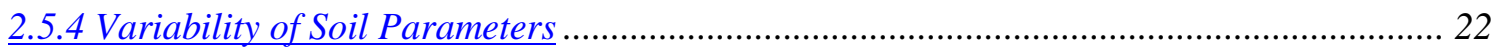

2.5.4.1 Sources of Variability in Soil Parameters ................................................................ 22

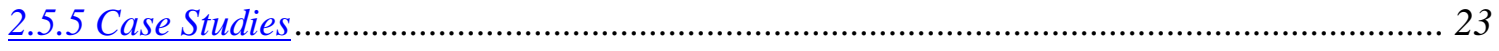

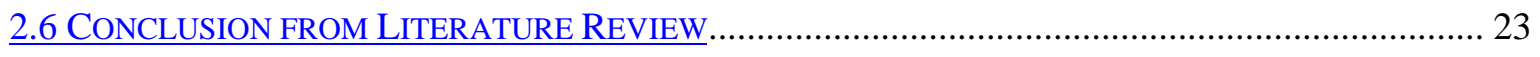

CHAPTER 3 COAL EXTRACTION METHODOLOGY _..................................................... 24

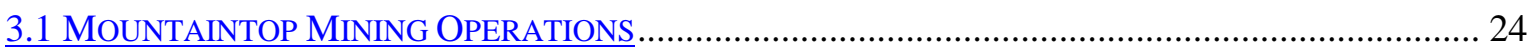




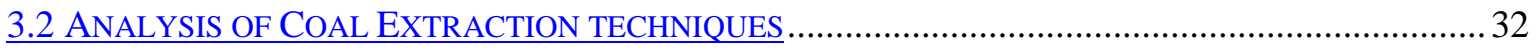

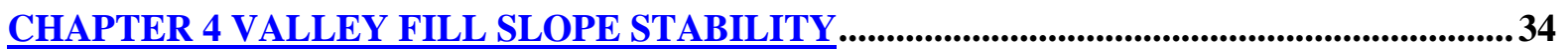

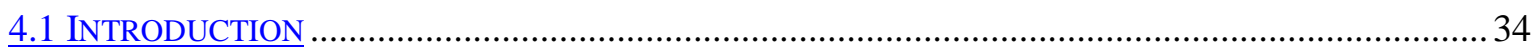

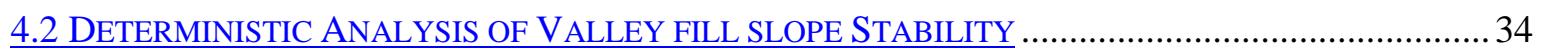

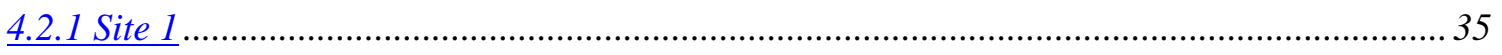

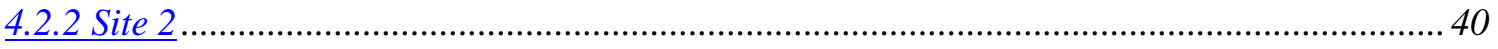

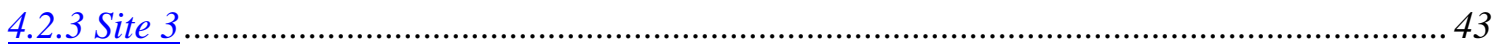

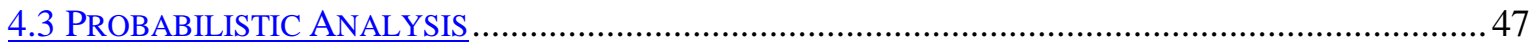

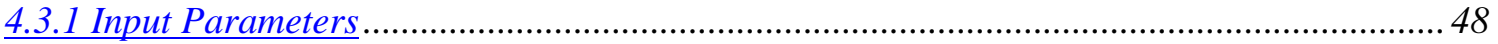

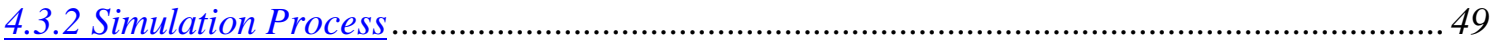

4.3.3 Interpretation of Monte Carlo Simulation................................................................................... 51

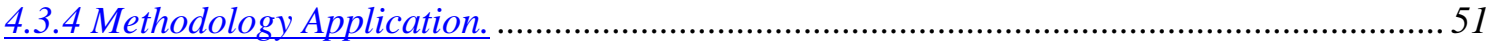

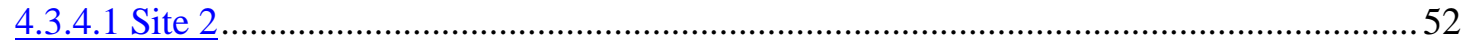

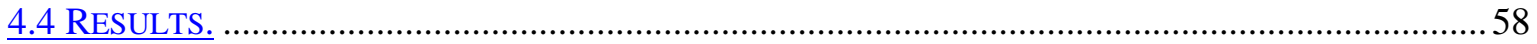

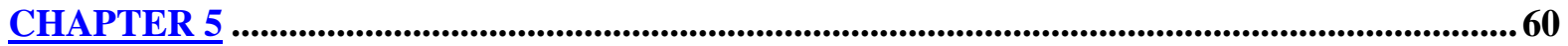

SUMMARY, AND CONCLUSIONS

5.1 SUMMARY

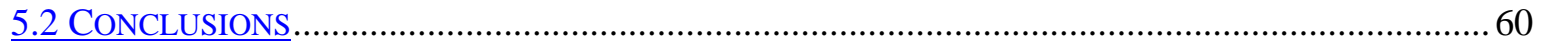

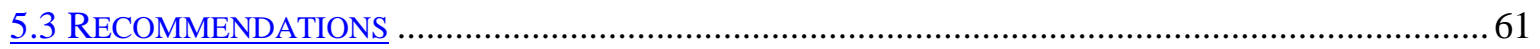




\section{List of Figures}

Figure 1-1: Map Showing Present and Projected Major MTR Activity in West Virginia..................... 2

Figure 2-1: Geologic columns, active mines (Source: Barata, 1995) .............................................. 8

Figure 2-2: Conceptual view of MTR mining with dragline advance (Source: Barata, 1995)............ 10

Figure 2-3: Valley fill configuration as per federal regulations....................................................... 11

Figure 2-4: Details of backfill volume displaced when complying with the performance standards.. 13

Figure 2-5: Modes of Circular Slope Failure (Source: Das, 1994) ..................................................... 16

Figure 2-6: Slope stability chart for soils with $\phi=0$ (Janbu 1968) .................................................. 18

Figure 2-7: Division of potential sliding masses into slices (Source: [3]) ........................................ 18

Figure 2-8: Bishop's method of slices (Source: Das, 1994) …........................................................ 19

Figure 2-9: General Monte Carlo Simulation Approach (Source: Hutchinson \& Bandalos, 1997) .... 22

Figure 3-1: Active Mountaintop mining operations (Arch Coal) in USA (Source: Arch Coal Inc.,).. 25

Figure 3-2: Mountaintop Mining Methodology (Source: Hobet 21 mine, Arch Coal)....................... 26

Figure 3-3: Phase\# 2 of mountaintop mining operation sequence, prestripping operation. (Source:

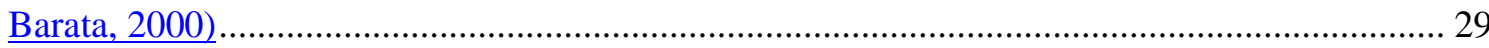

Figure 3-4: Phase \#3 of mountaintop mining operation sequence, upper seams are prestripped using

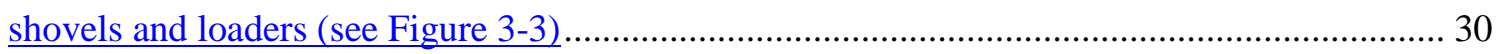

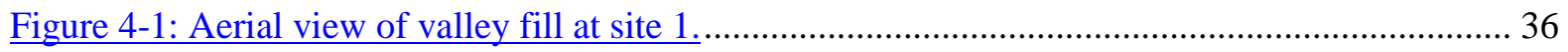

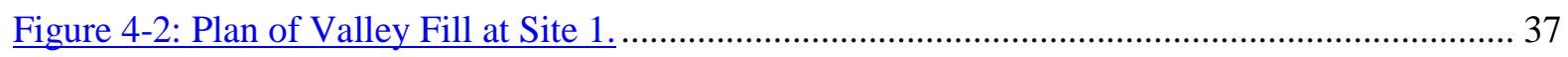

Figure 4-3: Slope stability analysis of Valley fill at Site 1, using Bishop's Simplified method of slices. .

Figure 4-4: Slope stability analysis of Valley fill at Site 1, using Janbu's method of slices. .............. 39

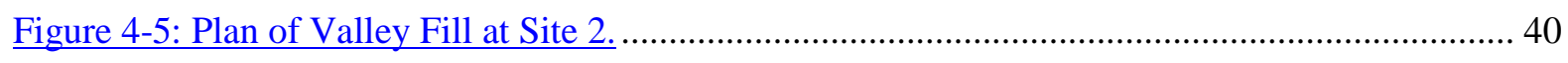

Figure 4-6: Slope stability analysis of Valley fill at Site 2, using Bishop's Simplified method of slices.

Figure 4-7: Slope stability analysis of Valley fill at Site 2, using Janbu's method of slices.

Figure 4-8: Slope stability analysis of Valley fill at Site 3, using Bishop's Simplified method of slices.

Figure 4-9: Slope stability analysis of Valley fill at Site 3, using Janbu's method of slices 46

Figure 4-10: Combination of Uncorrelated Input Parameters Distribution (Source: Peterson, 1999). 50

Figure 4-11: Combination of Correlated Input Parameters Distribution. (Source: Peterson, 1999).... 50

Figure 4-12: PERT distribution of input parameter Cohesion ( c $)$...................................................... 54 


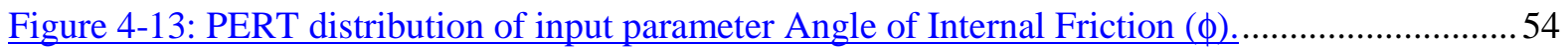

Figure 4-14: Cumulative distribution of FS, Circular Failure Surface at Site $2(\mathrm{n}=200) \ldots \ldots \ldots \ldots \ldots . . . . .56$

Figure 4-15: Cumulative distribution of FS, Circular Failure Surface at Site $2(\mathrm{n}=600) \ldots \ldots \ldots \ldots \ldots . . . . .56$

Figure 4-16: Sensitivity Analysis for Uncorrelated Input Parameters and FS ...................................57 


\section{List of Tables}

Table 3-1: Equipment in Fleet in a typical mountaintop removal (MTR) mine. ................................ 31

Table 4-1: Overburden fill thickness and Natural soil thickness from boring samples at Site1 .......... 35

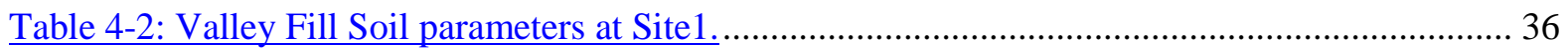

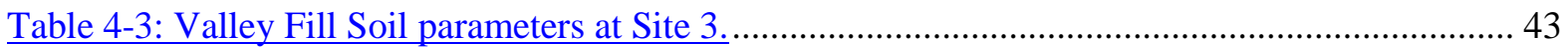

Table 4-4: XSTABL evaluation of response surface analysis. ......................................................... 52

Table 4-5: Summary of valley fill slope stability analysis at Site 1, 2, and 3.................................. 59 


\section{Glossary of Terms}

1. State program:

The WV surface coal - mining program approved under SMCRA consists of the WV surface mining law, regulations, policies, and procedures that OSM approved initially on January $21,1981$.

\section{Approximate Original Contour (AOC):}

The surface configuration achieved by back filling and grading of the mined area so that reclaimed area, including any terracing or access roads, closely resembles the general surface configuration of the land prior to mining and blends into, and complements the drainage pattern of the surrounding terrain, with all high walls and spoil piles eliminated. All mines are to be returned to AOC, unless they receive a variance from it [term defined in Subsection 22-3-3(e) of WVSCMRA and Subsection 701(2) of SMCRA].

3. AOC variance:

A regulatory authority may grant a variance or waiver from the requirement to restore a site to AOC if certain specified conditions are satisfied. State and Federal law provides for the following types of AOC variances: mountaintop removal (MTR), steep - slope, thick overburden, and remined areas.

\section{Excess spoil:}

Overburden material that is disposed of in a location other than the mine pit and that is not needed to achieve AOC.

5. Mountain top - removal mining (MTR):

Surface mining activities where mining operation removes an entire coal seam or seams running through upper fraction of a mountain, ridge, or hill, by removing substantially all of the overburden off the bench and creating a level plateau or a gently rolling contour, with no high walls remaining, and capable of supporting post mining uses in accordance with the requirements of this section [section 785.14 of SMCRA, 1977]. 
6. Contour Mining:

Surface mining technique that makes a cut into a hillside, creating a level bench with a high wall. A contour-mined area must be restored to AOC, including elimination of the high wall.

\section{Steep Slope Mining:}

Surface mining operation where the natural slope of the land, within the proposed permit area exceeds an average of $20^{\circ}$. 


\section{Chapter 1 \\ Introduction}

\subsection{Overview}

Many mining practices are used in the world today, depending on whether the mine is located underground, or on the surface (Chadwick, et. al., 1987). The mining type and practice is largely dependent on the location of the coal seam or seams, and how best to extract the coal in the cheapest way possible. The pertinent type of mining operation followed in the mountainous areas of the middle-eastern part of USA is Surface mining.

Surface mining methods comprise open pit (quarry, open cast), surface (area, contour, mountaintop removal), auger, dredging, or hydraulic (Johnson, et. al., 1996). Surface mining, is practiced to extract a large, relatively flat seam or seams of coal located at or near the surface. Spoil material is removed or 'shaved' back from the earth to extract the underlying coal seams (Chadwick, et. al., 1987). Large earth moving equipment and massive amounts of high explosive are used to remove overburden and gain access to the coal. Dump trucks, end loaders, and bulldozers are the most prominent types of equipment found on strip mine jobs today.

Mining operations carried out in mountainous areas form a class of its own. The three major types of surface coal mining operations carried out in middle-eastern part of USA are 1. Area mining, 2. Contour mining, and 3. Mountaintop removal mining (MTR). The public and the media have often called these types of mines "mountaintop-removal mines", even though that term applies only to one type of mountaintop operation in regulatory sense.

The location and the geology of the mine permit area, dictates the method of mining to be employed. Mining is carried out in an elevated track of nearly horizontal and gently folded strata. Lithologically, the rock units are composed mainly of beds of sandstone, interspersed with beds of siltstone, shale, coal, 
limestone and fire-clays. Surface mining of multiple seams by mountaintop removal (MTR) and contour mining is carried out in the Appalachian region of southwestern West Virginia. The present and projected major MTR mining activity in West Virginia is shown in Figure 1-1.

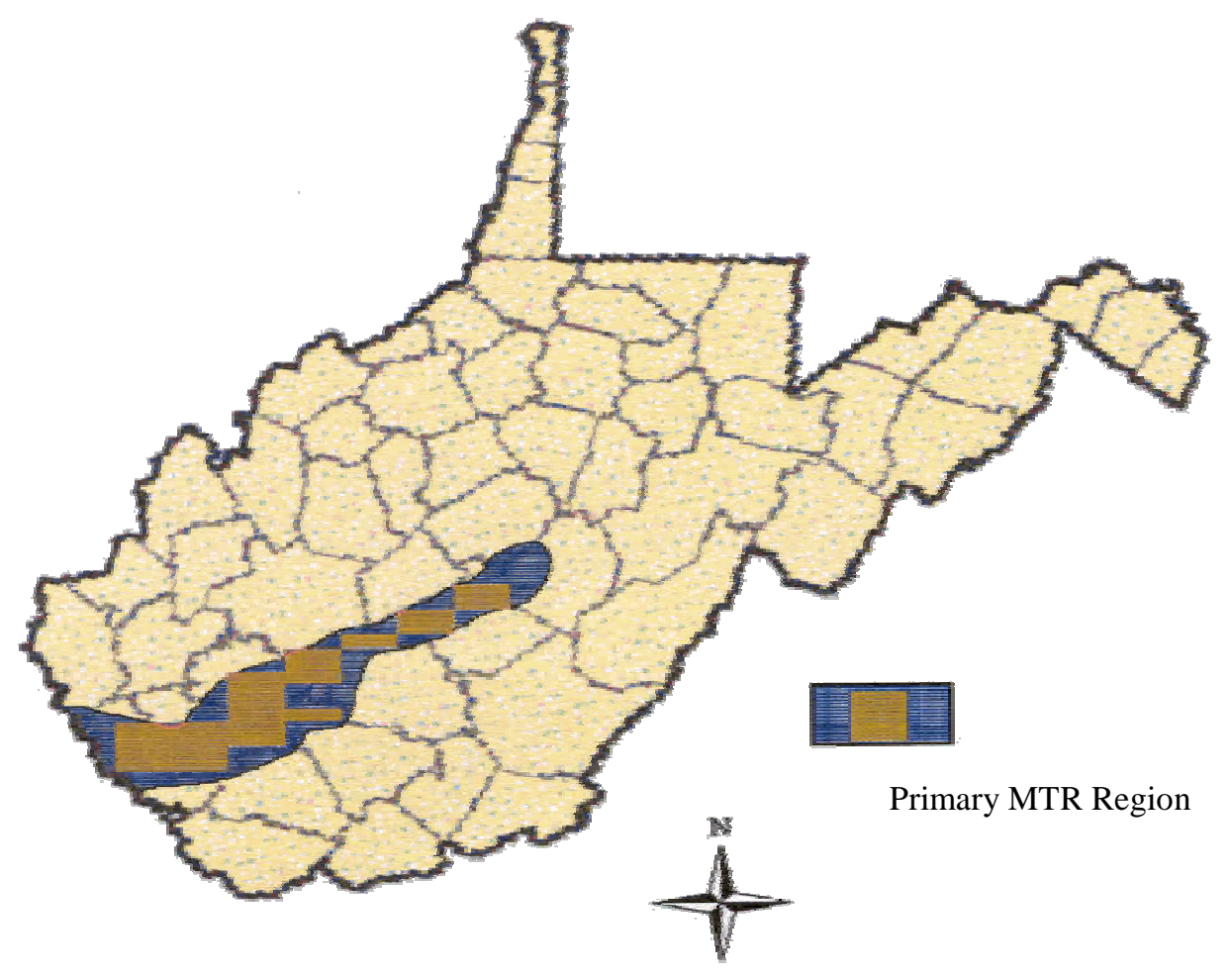

Figure 1-1: Map Showing Present and Projected Major MTR Activity in West Virginia

(Source: West Virginia Geological and Economic Survey-October, 1998)

Mining operations carried out in mountainous areas will be referred to as "mountaintop operations" for the rest of this document. Three types of mining practices are included in the term "mountain top operations"[1]. These types are:

1. "Mountaintop-removal (AOC variance) operations": Mines which remove all of the coal seam or seams in the upper fraction of a mountain or ridge and request a mountaintop-removal variance from AOC. Only this kind of operation constitutes a mountaintop-removal mine in the regulatory sense. 
2. Mines, which remove all of the coal seam or seams in the upper fraction of a mountain or ridge and return the land to AOC.

3. Mines in the steep-slope areas (slopes exceeding 20 degrees), which have received steep-slope AOC variances.

Of the types of mountaintop operations mentioned, operations falling into categories $1 \& 2$ only were analyzed. The southern part of West Virginia where most MTR sites are located, has high relief, and occur in very steep, and mountainous country with deep valleys, and gorges. They are also very remote in terms of location from population centers and or major highways. (Charleston Gazette, 1998). These conditions associated with MTR sites have enabled coal companies to dispose of the spoil material from mines in the valleys and hollows adjacent to the mine sites, thereby keeping costs low (Charleston Gazette, 1996). Due to this, MTR is sometimes referred to as 'valley fill mining', or head of hollow mining' (EPA Report, 1974; 1979; 1981; Charleston Gazette, 1998). As cited from the Governor's Task Force Report on MTR in W.Va. (1998), "MTR involves the removal of a mountain, ridge, or hill, with overburden removal following the coal seam elevation from one outcrop to another".

Mining engineers are responsible for the mining activity as well as the ramifications there after. We are responsible for the analysis of the coal extraction and spoil handling techniques in mountainous areas. The mining methodology used in these areas is unique, and thorough understanding of the spoil handling techniques is required, as spoil handling is the issue of controversy here.

The ability of mining engineers to accurately analyze the mining methodology for mountainous areas is compromised by a variety of factors. These may be broadly classified as theoretical and practical considerations. Theoretical considerations include approximations and assumptions made for mine model development. Practical considerations include an inability to adequately sample and accurately test for the parameters used in the mine layout, excess spoil disposal plans, slope stability analysis etc. The net result of these considerations is that the exact analysis of the entire mining operation cannot be made. Hence, two major activities 
of mountaintop operation 1. Coal Extraction and 2. Valley fill Stability were analyzed.

\subsection{Problem Statement}

Owing to its unique mining operations, and the environmental effects associated with it, mountaintop removal (MTR) method of mining has become an issue of public concern. The pertinence of the present mountaintop mining operations and reclamation techniques, with respect to being in compliance with Surface Mining Control and Reclamation Act of 1977 (SMCRA), as well as both Federal and State regulations is at question.

The hypothesis of this research is the analysis of coal extraction and spoil-handling techniques used in mountainous areas can answer the environmental concerns on mountaintop operations. Mining engineers are responsible for the analysis of valley fill slopes and design of either the slope's geometry or a structure to restrain the slope. Traditional slope stability analysis uses single value estimates for each variable in the slope stability equations. Consequently traditional analysis methods yield single estimates of a slope's stability. Probabilistic modeling method uses information about the probability distribution of the slope's characteristics to determine the probability distribution of the output of the analysis. . Knowledge of the probability distribution of the output allows the engineer to assess the probability of slope failure. Therefore, an allowable risk criterion can be used to establish a consistent target for the design process.

\subsection{Objective}

To analyze the coal extraction and spoil handling techniques in mountainous areas. The coal extraction methodology is analyzed from the mine design phase to reclamation phase. The valley fill slope stability is analyzed using traditional as well as probabilistic modeling methods. Through Monte Carlo simulation, the distribution of each input parameter is used with traditional behavior equations to produce a probability distribution for the output of the analysis. Allowable risk 
criterion is then applied to the output distribution to select the slope design parameters that have an acceptable level of risk.

\subsection{Analysis approach}

A literature review was performed to document the mountaintop mining methods, pertinent governing regulations, AOC requirements, and AOC model. This review also introduces traditional and probabilistic methods for slope stability analysis. Information on the variability of the input parameters was sought to quantify their probability distributions. A methodology for conveniently combining the traditional analytical models with the distribution of input parameters was sought. The Monte Carlo simulation method was identified as a suitable modeling method. The @RISK software package for Microsoft Excel was identified as a convenient method for developing a Monte Carlo simulation of output variables of slope stability analysis of valley fill.

\subsection{Thesis Format}

The main objective of this research is to analyze the coal extraction and spoil handling techniques in mountainous areas. The element of uncertainties in the input parameters for the analysis of mountaintop mining operations is unavoidable. A probabilistic approach offers a way to incorporate all factors that are associated with the input parameters. This approach is used in the analysis of valley fill slope stability and in the project evaluation of MTR projects.

Chapter 2 presents a literature review. The geology of the mountainous areas is summarized. Pertinent mountaintop mining methods and regulations are introduced. The state of the practice of slope stability analysis is summarized. Finally, probabilistic analysis using Monte Carlo Simulation is introduced.

Chapter 3 lays out the analysis of mountaintop operations. Emphasis is made on Mountaintop Removal (MTR) mining, and Contour mining. The various phases of MTR operations are explained. Finally, the important concerns of the MTR methodology are answered. 
Chapter 4 demonstrates the analyses of valley fill slope stability. The deterministic method is applied to three case studies from the field. The first case study is selected, to study the long-term stability of valley fills. The second case study is selected, to analyze the stability of a pure overburden slope. The third case study is selected to analyze the stability of a slope with lower relief and greater stretch.

Chapter 5 presents the conclusions and recommendations of the research. Included in chapter 5 are general findings from the three case studies used for analysis of valley fill slope stability. 


\section{Chapter 2 \\ Literature Review}

\subsection{Introduction}

Mountaintop mining methods, and theory of slope stability have received extensive treatment in the literature. Several methods of mountaintop mining are followed in the Appalachian region. The literature focuses on 1. Geology of the Appalachian region, 2. MTR and contour mining, 3. Governing regulations and AOC model.

On slope stability several methods and analytical techniques have been developed to describe a variety of geometric and soil characteristics. This chapter presents a review of slope stability analysis methods, including both deterministic and probabilistic concepts. The variability within valley fill parameters is summarized in this review. Finally, several case studies of valley fill slope stability analysis are summarized.

\subsection{Geology}

The Appalachian plateau province is an elevated tract of nearly horizontal and gently folded strata.

This area is underlain by horizontally bedded sedimentary rocks of Pennsylvanian age. Lithologically, the rock units are composed mainly of massive beds of sandstone, interspaced with beds of siltstone, shale, coal, limestone and fire-clays. The Pennsylvanian rocks are divided into four major stratigraphic groups. They include, in ascending order, the Pottsville group, the Allegheny formation, the Conemaugh group and the Monangahela group [2].

The general rock sequence in the Applachia is bound at the base by the Coalburgh sandstone. Other significant stratigraphic units, in ascending order are Stockton seam, Clarion seam, and Kittanning seam. Within the numerous coal seams are various splits of coal. The split thickness ranges from 10 to $32 \mathrm{in}$. To be considered minable, a split of coal should be at least 6 in. thick. The typical lithology of the area is shown in Figure 2-1. 
Upper Kitaning (402)

Lower Kittaning (400)

Opper Five Block (380)

Lower Five Block (340)

Upper Stockton Rider (320)

stockton (304)

Lower Stockton Rider (280)

Coalburg Rider (260)

Calburg Seams $(210-200)$

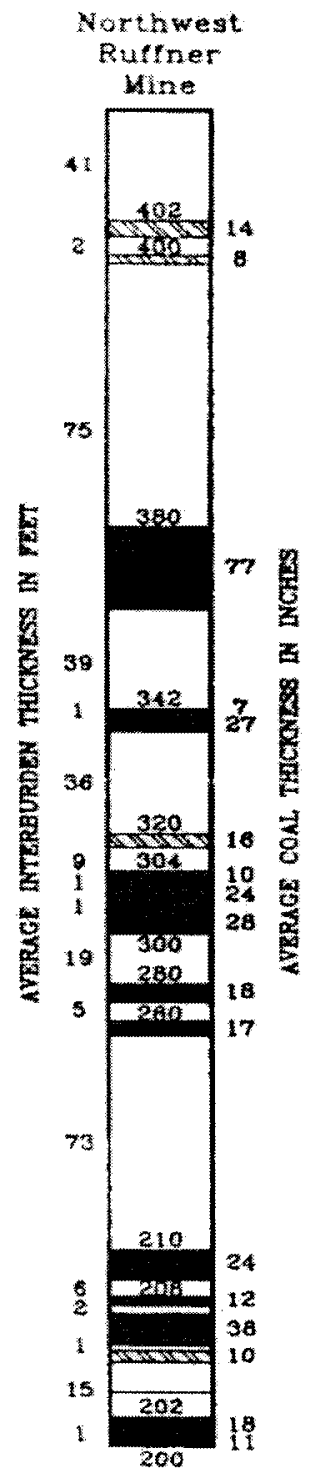

Note:

380 Seam Extensively Deep Mined 210 Seam Sporadio Throughout The Reserve

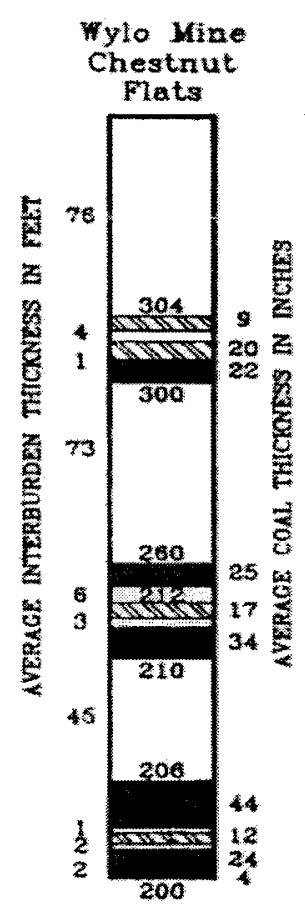

LECEND

\begin{tabular}{|c|c|c|c|}
\hline Seam Number & $\square_{\text {interburtien }}$ & High Quality & Low Quality \\
\hline
\end{tabular}

Figure 2-1: Geologic columns, active mines (Source: Barata, 1995) 


\subsection{Mountaintop Mining Operations}

The two main mountaintop-mining operations of interest are Contour mining, and Mountaintop removal (MTR) mining.

\subsubsection{Contour Mining}

The steep slopes in the mountains of Appalachia generated a method of mining referred to as contour mining. During the late 1960s and early 1970s, contour mining was introduced, using front-end loaders with bucket capacities of more than $7 \mathrm{~m}^{3}$. The basic operation in contour mining is to drive a contour cut on the lowest minable seam. This mining provides control drainage and a bench to prevent down slope placement of material [2].

Contour mining resulted in low mining ratios, but also lengthy outcrop disturbances (highwalls) and numerous environmental problems.

\subsubsection{Mountaintop removal (MTR) mining}

The definition of mountaintop removal method is given in the glossary. The mountaintop removal method of surface mining began during the 1970s. The top of the mountain is removed to uncover the most economically minable coal seams. The overburden and interburden removed are placed in the valley fills and back stacked on previously mined areas as required to produce the coal. The conceptual view of mountain top removal (MTR) mining with dragline advance is shown in Figure 2-2.

Contour mining incorporated into a MTR operation helps control drainage, minimize down slope over shots and balance the mining ratios. While MTR optimizes the coal reserve, the nature of this method results in coal being mined with higher mining ratios. This is due to the topography of the area. However, another contributor to these ratio increases includes previous mining operations in the area. 


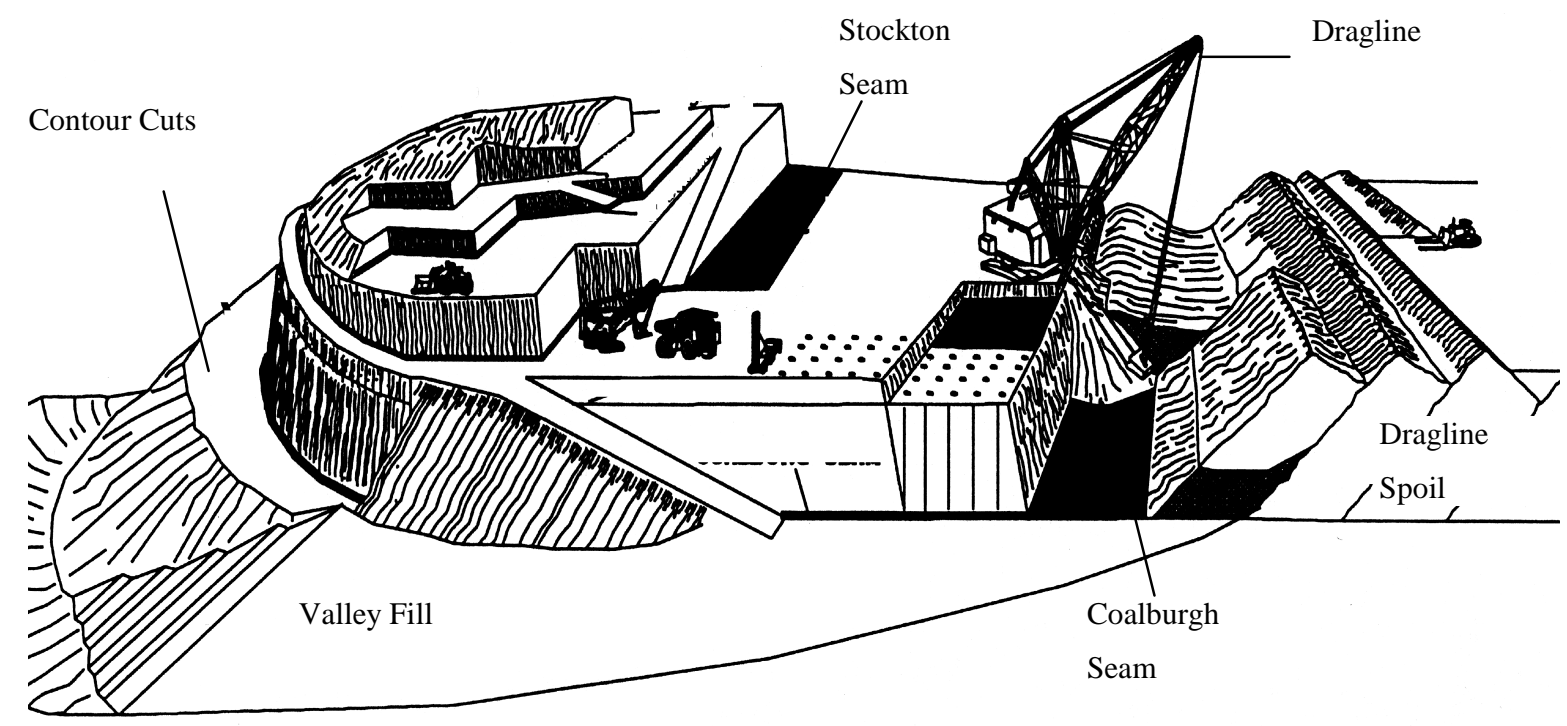

Figure 2-2: Conceptual view of MTR mining with dragline advance (Source: Barata, 1995)

\subsection{Governing Regulation s and AOC Model}

Prior to the formulation of SCMRA in 1977, mining was not regulated. Mining operations in the Appalachian region left poorly reclaimed areas. The absence of any regulatory authority for monitoring both the mining and reclamation activities resulted in rendering the abandoned mine land to no useful use

\subsubsection{Federal Regulations}

The Federal regulations pertaining to mountaintop-removal operations are found at 30 C.F.R. $\delta 785.14$ and Part 824. The valley fill slope configuration, as per federal regulations is shown in Figure 2-3.

1. A requirement for compliance with the alternative post mining land use provisions of 30 C.F.R sec.816.33 (a).

2. A specification that final graded slopes on the plateau portion of the operation not exceed $1 \mathrm{v}$ : $5 \mathrm{~h}(20 \%)$. (This specification is in for the flat plateau portion formed on the top of the valley fill.) 
3. A requirement that plateau out slopes attain a minimum static safety factor of 1.5 or that they not exceed $1 \mathrm{v}$ : $2 \mathrm{~h}(50 \%)$. (This requirement is for the slope between terraces formed in the formation of valley fill. A slope not greater than $1 \mathrm{v}$ : $2 \mathrm{~h}$ is required, as this is maximum safe slope for operation of tracked-equipment.)

4. A requirement that the resulting level or gently rolling contour be graded to drain inward from the slope.

5. Prohibition on damage to natural watercourses applies only to watercourses below the lowest coal seam to be mined.

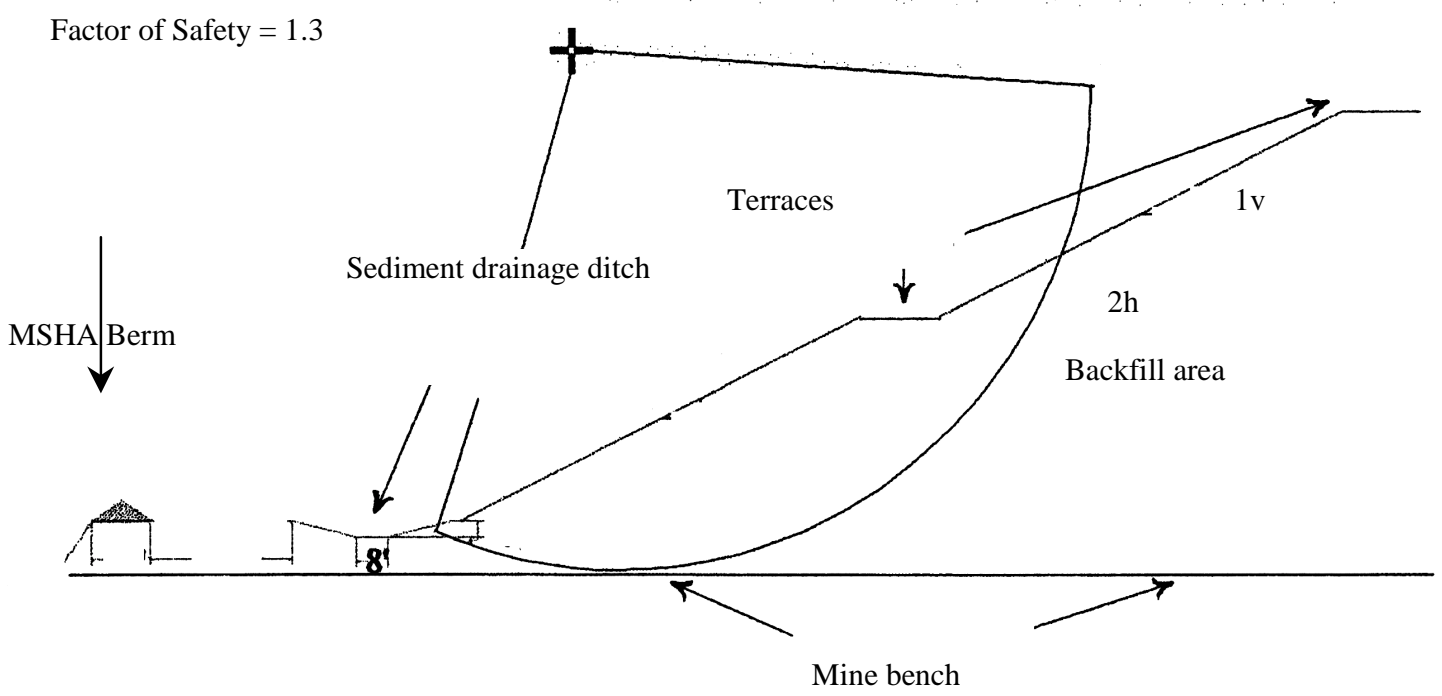

Figure 2-3: Valley fill configuration as per federal regulations. 


\subsubsection{State Regulations}

Pursuant to Subsection 22-3-13(C) of the WVSCMRA, the State may grant a permit with a mountaintop-removal variance only after finding that:

1. The proposed post mining land use constitutes an "equal or better use;"

2. The proposed use will be compatible with adjacent land uses and existing land use plans;

3. The application contains specific plans and assurances that the proposed use will be 1) compatible with the adjacent land uses; 2) practicable with respect to financing and completing the proposed use; 3) supported by commitments from public agencies where appropriate; 4) planned pursuant to a schedule that will integrate the mining operation and reclamation with the post-mining land use; and 5) designed by an approved person to assure the stability, drainage, and configuration necessary for the intended use of the site.

\subsubsection{AOC Model}

The key variables found in the AOC definition, influencing AOC determination are: configuration, backfilling and grading, disturbed area, terracing or access roads, closely resembles, and drainage patterns. These variables, for analysis purposes can be logically grouped into 3 focus areas: 1) Configuration, 2) Stability, and 3) Drainage. These focus areas are addressed through a formula-like model that portrays these variables in a process for determining what post-mining surface configuration meets the AOC definition.

Variables in the formula are as the following:

OC: Pre-mining configuration, or volume of backfill material to replicate the original contours of the undisturbed area proposed to be mined. 
SR: Backfill volume displaced due to compliance with stability requirements.

DR: Backfill volume displaced due to compliance with drainage control requirements.

SCR: Backfill volume displaced due to compliance with sediment control requirements.

AR: Backfill volume displaced due to compliance with access/maintenance requirements.

AOC: Volume of backfilled spoil required to satisfy the SMCRA regulations for approximate original contour.

The details of backfill volume displaced are shown in Figure 2-4. Based on the terms given above, the following formula determines the amount of backfill, which must be returned to the mined area to satisfy AOC.

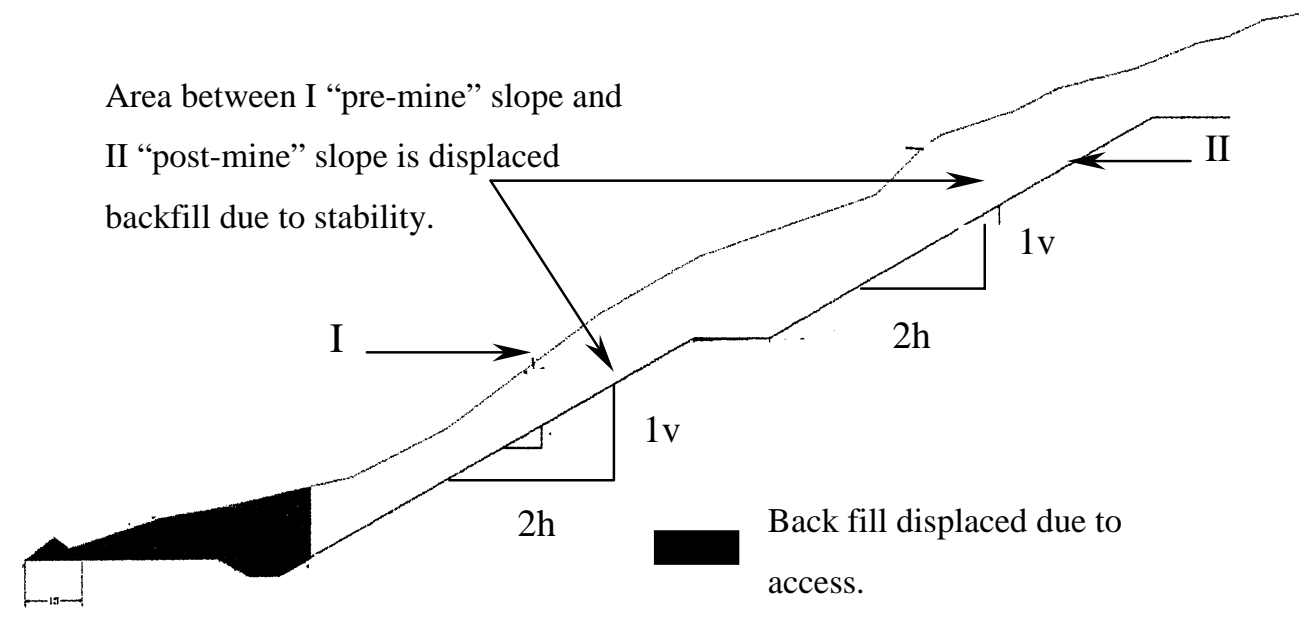

Figure 2-4: Details of backfill volume displaced when complying with the performance standards. 


$$
A O C=O C-S R-D R-S C R-A R
$$

Equation 2-1

Total Spoil Material (TSM): Total spoil material is all of the overburden (OB) plus interburden (IB) that must be handled as a result of the purposed mining operation. TSM value is expressed as bank cubic yards (bcy).

$T S M=(O B+I B) * B F$; Where BF is the Bulking Factor

Equation 2-2

Spoil Placement Areas: Spoil can be placed either in decoaled area or backfill (BFA), or in excess spoil disposal area (ESD), i.e. valley fills

The Excess Spoil (ES) will be

$$
E S=T S M-B F A
$$

Equation 2-3

$\mathrm{BF}$ : Backfill is the material placed in the mined out area to attain original configuration (OC), or Approximate Original Configuration (AOC)

Therefore, from Equations 2-1, 2-2, 2-3

$$
E S=T S M-A O C
$$

Equation 2-4

Thus the excess spoil determined is handled by filling it in adjacent valley or by backstacking. The valley fills so formed should be in compliance with Federal regulations.

The AOC model is used to determine the excess spoil disposal plans and valley fill final configuration. The stability of these valley fills is at question. The analyses of excess spoil disposal plans and valley fill stability helps in developing better strategy for reducing the impact of MTR mining on the environment. 


\subsection{Slope stability}

Analyzing stability of overburden fill (valley fill) slopes is not straightforward. The main point in analyzing a slope is to investigate the various modes of failure, and recommend methods to prevent slopes from failing.

\subsubsection{Modes of slope failure}

Depending on the geological conditions, slopes can fail in different modes. The failure forms of interest for this research are circular failure in overburden slides. Circular failure surface analysis is used for thick residual or colluvial soil, soft marine clay, shale, and firm cohesive soil (Hunt, 1984). (Source. Jennifer L. Peterson, Probability Analysis of Slope Stability, 1999)

There are two general scales of slope-stability problems, gross stability and local stability. Gross stability refers to large volumes of soil, and gross instability would involve large rotational-type shear failures. Local stability refers to something much smaller and examples of local stability are small shear failures or sloughing, slope erosion due to surface drainage, and by concentrated ground water flow. Gross instability (may be lead by an unattended local instability) is the major problem in Overburden slopes.

\subsubsection{Traditional Slope Stability Analysis Methods}

For the purposes of this review, traditional slope stability analysis methods are defined as those which treat slopes as deterministic situations with uniquely defined parameters. These methods are widely documented in geotechnical textbooks. The following description is based on the work of Das (1994). Traditional methods use principles of static equilibrium to evaluate the balance of driving and resisting forces. The factor of safety is defined as the resisting forces divided by the driving forces, or alternatively as the shear strength divided by the calculated shear stresses. A factor of safety greater than one indicates a stable slope; a value less than one indicates impending failure. For a given slope, a factor of safety of one identifies the critical height of a slope. The modes of circular slope failure in homogeneous clay are shown in Figure 2-5. 
(a) Toe Circle
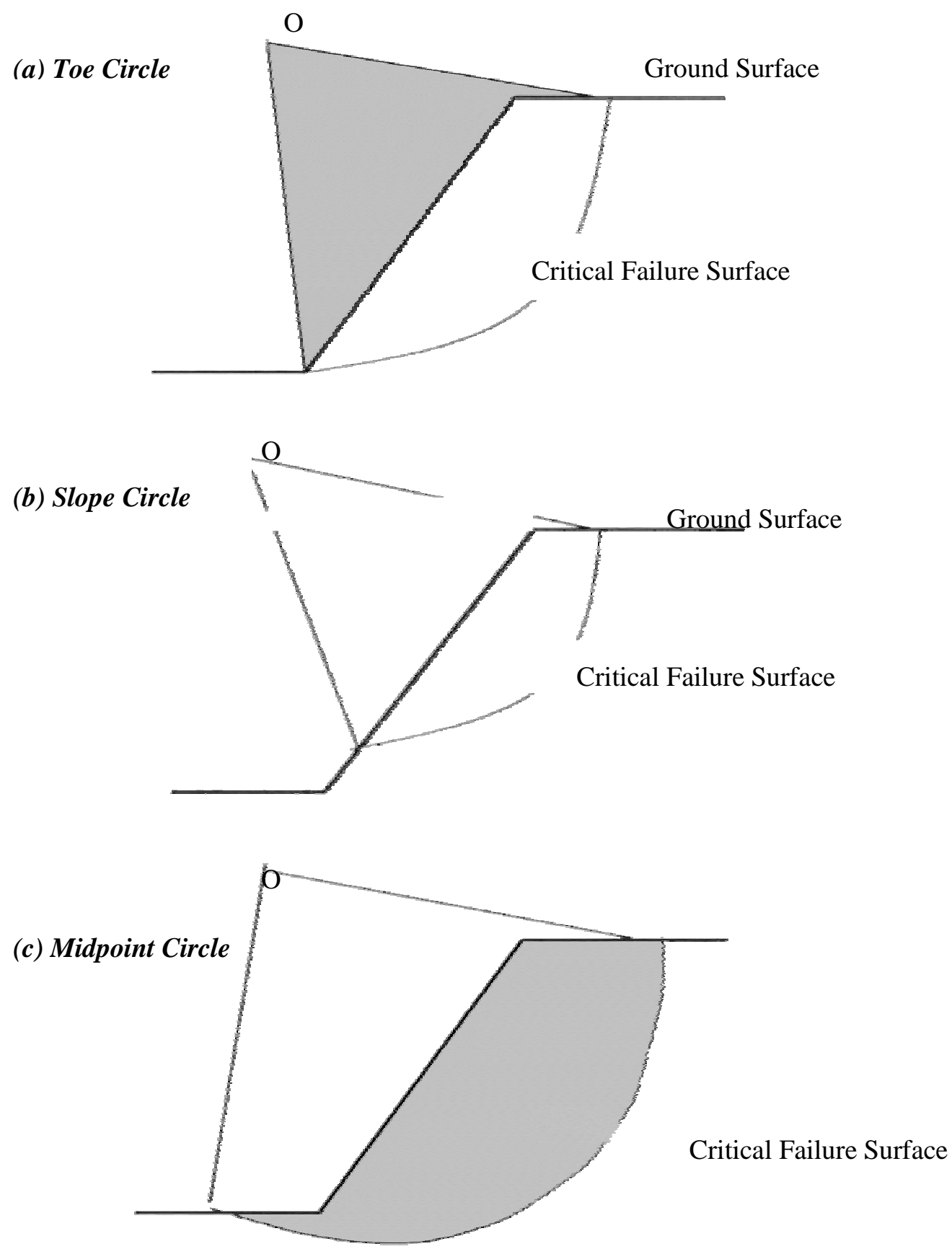

$$
F S=c / \gamma H m
$$

Figure 2-5: Modes of Circular Slope Failure (Source: Das, 1994) 
For a circular failure plane analysis, the computed factor of safety is a function of the assumed location of the center of the circle. The critical failure surface produces the minimum factor of safety. The critical failure surface location is determined by trial and error. Janbu (1968) developed stability charts for slopes with $\phi=0$. These charts assign a stability number $N_{0}$ to slopes, as a function of the slopes horizontal angle ( $\beta$ ), cohesion ( c ), Unit weight $(\gamma)$ and the height of the slope from the ground surface $(\mathrm{H})$. The slope stability number is defined as $m=c / \gamma H(F s)$

Equation 2-6

Figure 2-6 gives the stability number values for soils with angle of friction equal to zero.

The traditional slopes analysis methods are as follows:

a) Infinite slope without seepage.

b) Infinite slope with seepage.

c) Finite slope with planar failure surface.

d) Circular failure in homogeneous clays. $(\phi=0$ and $\phi>0)$

All the above-mentioned methods assume the soil is homogeneous. This is assumption is not valid for valley fill slopes. The method of slices was developed to be able to account for the heterogeneity of soils in slope stability analysis. All of the practically useful methods of analysis are methods of slices, so called because they subdivide the potential sliding mass into slices for purposes of analysis [3]. Usually the slice boundaries are vertical, as shown in Figure 2-7. Two useful simplifications are achieved by subdividing the mass into slices:

1. The base of each slice passes through only one type of material, and

2. The slices are narrow enough that a straight line can accurately represent the segments of the slip surface at the base of each slice.

The equilibrium conditions can be considered slice by slice. If a condition of equilibrium is satisfied for each and every slice, it is also satisfied for the entire mass. The forces on a slice are shown in Figure 2-8. 


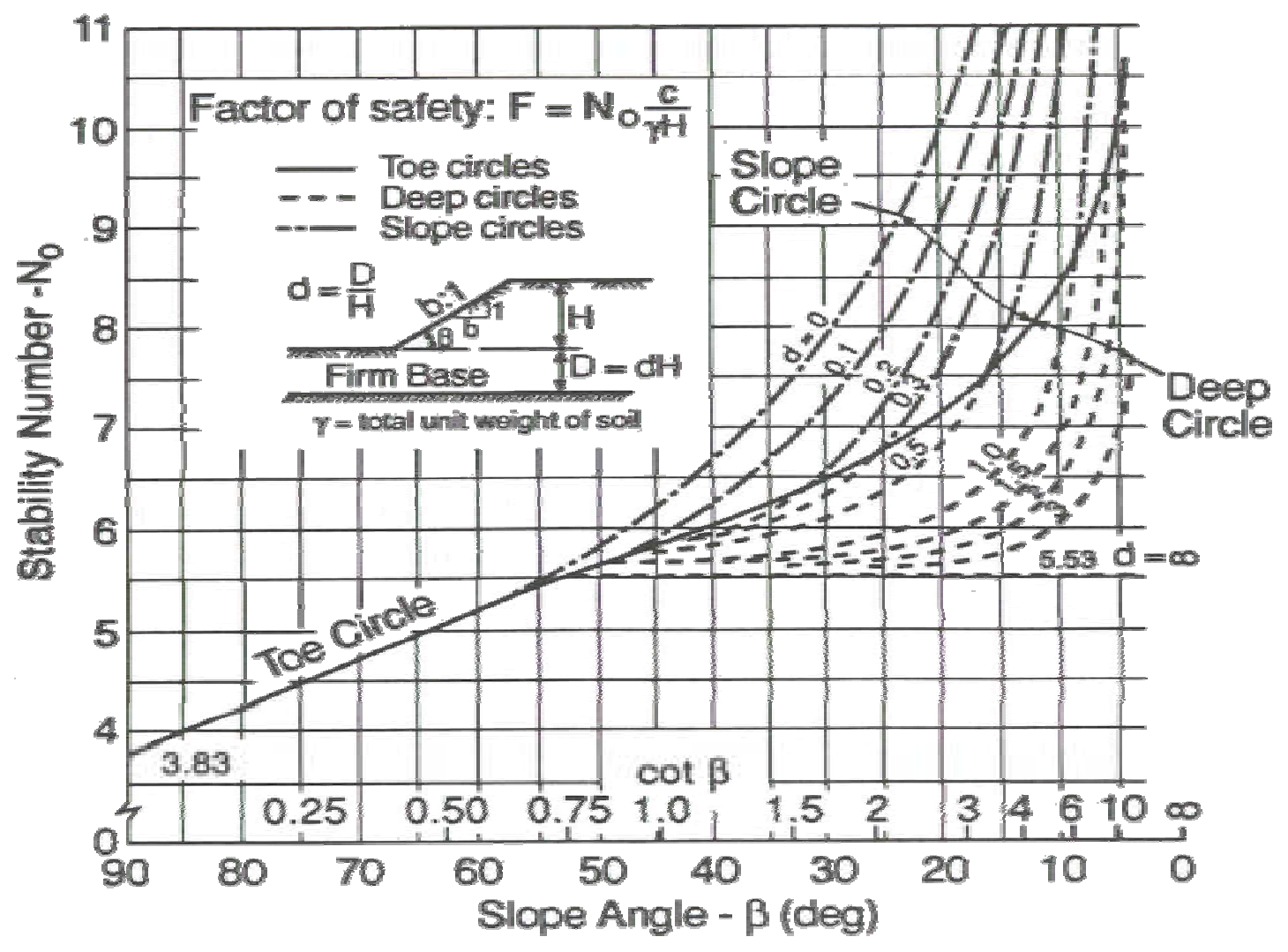

Figure 2-6: Slope stability chart for soils with $\phi=0$ (Janbu 1968)
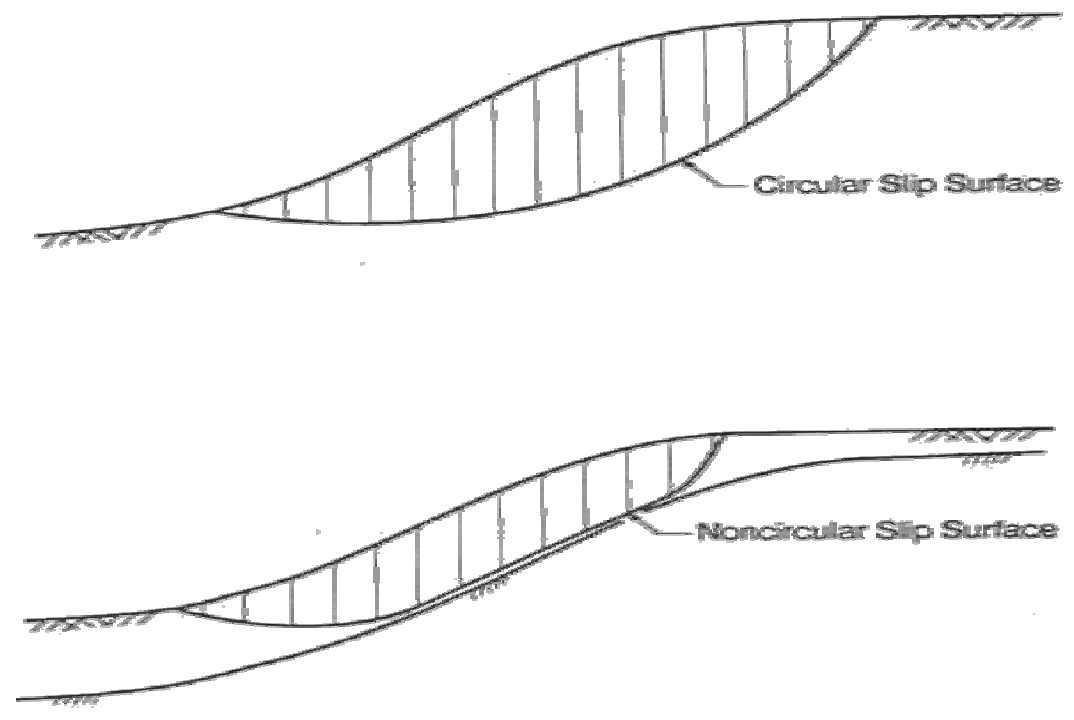

Figure 2-7: Division of potential sliding masses into slices (Source: [3]) 


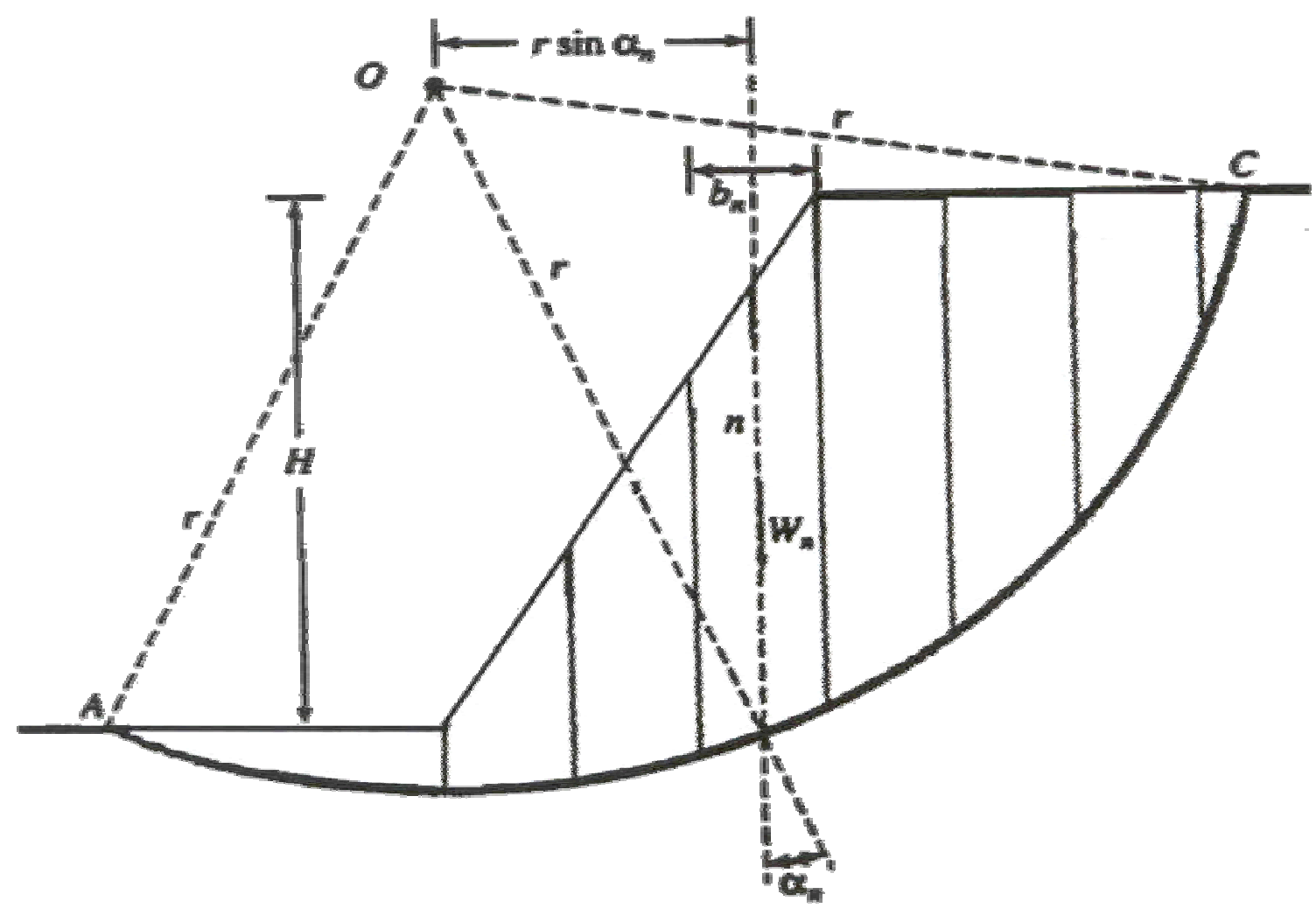

Figure 2-8: Bishop's method of slices (Source: Das, 1994)

Bishop's method of slices do account for the forces acting on each side of each slice. Equations 2-7 through 2-9 are used to find the factor of safety (Fs) for the ordinary method of slices and the modified Bishop's method (Das, 1994).

$$
F S=\frac{\sum_{n=1}^{n=p}\left(c \Delta L_{n}+W_{n} \cos \alpha_{n} \tan \phi\right)}{\sum_{n=1}^{n=p} W_{n} \sin \alpha_{n}} \quad \text { Equation 2-7 }
$$




$$
F s=\frac{\sum_{n=1}^{n=p}\left[\left(c b_{n}+W_{n} \tan \phi\right) \frac{1}{m_{\alpha n}}\right]}{\sum_{n=1}^{n=p} W_{n} \sin \alpha_{n}}
$$

$$
m_{\alpha n}=\cos \alpha_{n}+\frac{\tan \phi \sin \alpha_{n}}{F s}
$$

Since the factor of safety for the Bishop's method is on both sides of the equation, a trial and error solution method is required. Several computer programs are available for solution of the Bishop method and other modifications to the method of slices. XSTABL, developed by Interactive Software Design Inc., Moscow, Idaho, is a commonly used program for the method of slices analysis.

\subsubsection{Probabilistic Slope Stability Analysis Methods}

(Source: Jennifer Lynn Peterson, Probability analysis of Slope Stability, 1999)

Uncertainties in soil properties, environmental conditions, and theoretical models are the reason for a lack of confidence in deterministic analyses of gross failures in overburden failures (Kenny T. C, 1971). Arthur Casagrande, in the Terzaghi Lecture of 1964, presented the definition of calculated risk for applications within geotechnical engineering (Whitman, 1984). He emphasized that uncertainties are inherent to any project and the levels of uncertainties should be recognized. He stated, that calculated risk needs to be recognized and dealt with in two steps:

1. The use of imperfect knowledge, guided by judgement and experience, to estimate the probable ranges for all pertinent quantities, that affects the solution of the problem.

2. The decision on an appropriate level of safety, or degree of risk, taking into consideration economic factors and the magnitude of losses that would result from failure. 
Compared to a deterministic analysis, probabilistic analysis takes into consideration the inherent variability and uncertainties in the analysis parameters. Judgements are quantified within a probabilistic analysis by producing a distribution of outcomes rather than a single fixed value. Thus, a probabilistic analysis produces a direct estimate of the distribution of either the factor of safety or critical height associated with a design or analysis situation.

There are several probabilistic techniques that can be used to evaluate geotechnical situations. Specifically, for geotechnical analysis, researchers have conducted probabilistic evaluations using: Monte Carlo simulations, Point Estimate Method, and in conjunction with a probabilistic analysis a reliability assessment.

\subsubsection{Monte Carlo Simulation}

The Monte Carlo method was developed in 1949 when John von Neumann and Stanislav Ulam published a paper, "The Monte Carlo Method." The Neumann and Ulam concept specifically designated the use of random sampling procedures for treating deterministic mathematical situations. The foundation of the Monte Carlo gained significance with the development of computers to automate the laborious calculations.

Figure 2-9 illustrates a general schematic for a Monte Carlo simulation (Hutchinson \& Bandalos, 1997). The first step of a Monte Carlo simulation is to identify a deterministic model where multiple input variables are used to estimate a single value outcome (Torries, 1998). Step two requires that all variables or parameters be identified. Next, the probability distribution for each independent variable is established for the simulation model, (i.e., normal, beta, log normal, etc). Next, a random trial process is initiated to establish a probability distribution function for the deterministic situation being modeled. During each pass, a random value from the distribution function for each parameter is selected and entered into the calculation. Numerous solutions are obtained by making multiple passes through the program to obtain a solution for each pass. The appropriate number of passes for an analysis is a function of the number of input parameters, 
the complexity of the modeled situation, and the desired precision of the output. The final result of a Monte Carlo simulation is a probability distribution of the output parameter.

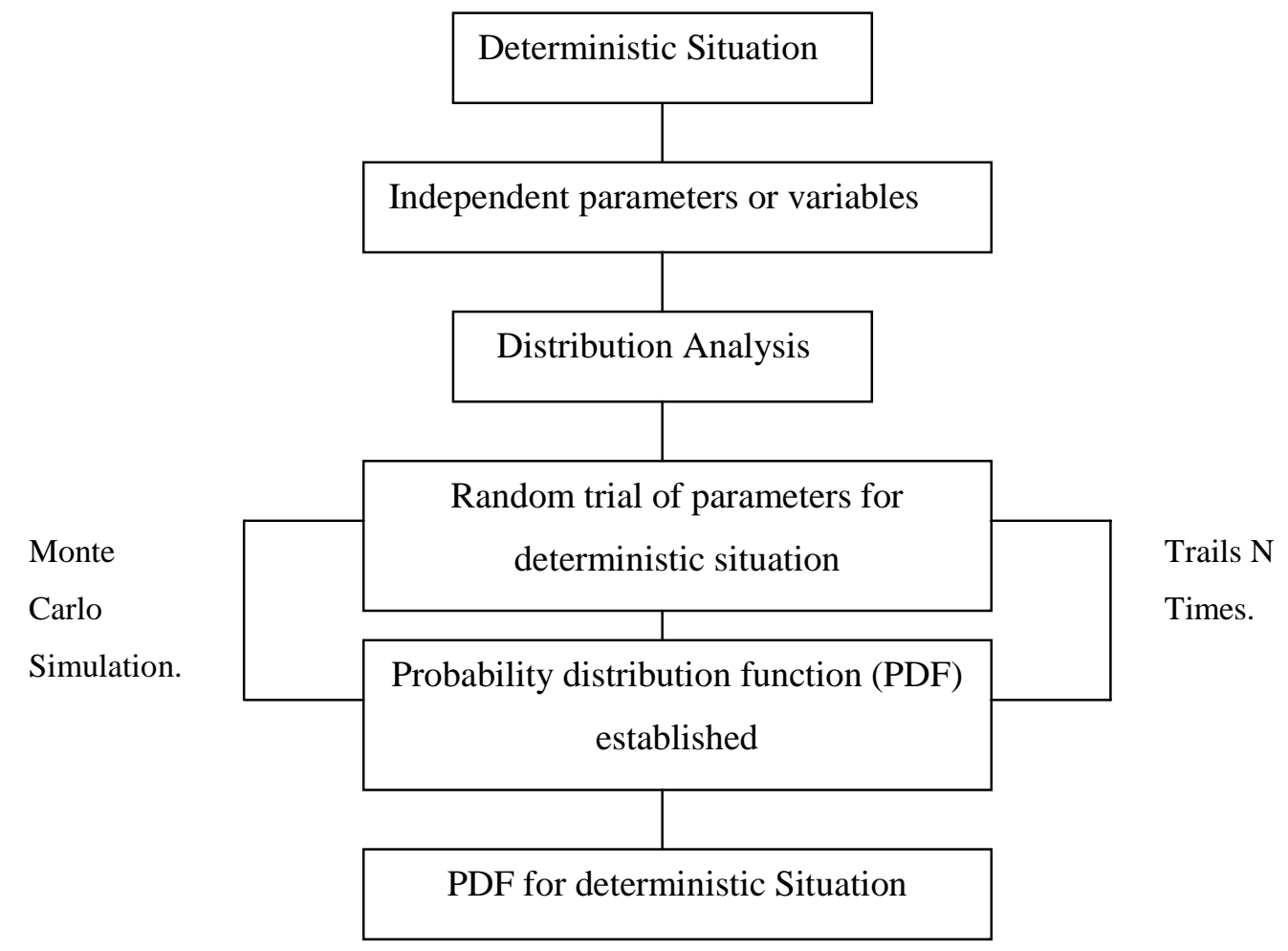

Figure 2-9: General Monte Carlo Simulation Approach (Source: Hutchinson \& Bandalos, 1997)

\subsubsection{Variability of Soil Parameters}

To account for the uncertainties in slope stability, the given input parameters have been defined as random variables. For every random variable, there is a mean $(\mu)$, standard deviation $(\sigma)$, variance $\left(\sigma^{2}\right)$, and probability distribution function (PDF).

\subsubsection{Sources of Variability in Soil Parameters}

Uncertainties within soil properties arise from either scatter in the data or systematic testing and modeling discrepancies. Data scatter emanates from the 
variability in the soil profile or random testing errors. Systematic discrepancies arise from bias in either the sampling process or test methods. Systematic errors are artifacts of inappropriate sampling and testing methods and should be eliminated. Data scatter is a function of the inherent variability in the materials and test methods and must be quantified.

\subsubsection{Case Studies}

Probabilistic approaches are used to analyze the slope stability of two valley fill overburden slopes, with natural soil undercover, and one valley fill overburden slope with no natural soil undercover.

Response Surface Method (RSM) (Wong, 1985) was selected as a tool to overcome the incompatibilities between the Bishop's method and a Monte Carlo Simulation. The probabilistic analysis of circular failure slopes using RSM techniques is presented in Chapter 4.

\subsection{Conclusion from Liter ature Review}

The literature review provided the background of Mountaintop mining operations, regulations governing MTR operations. It laid a foundation for the analysis of coal extraction techniques and valley fill slope stability analysis techniques. The geology of the Appalachia area, forces mining engineers to adopt complex mining methods for coal extraction. A combination of deterministic and probabilistic methods will be adopted for the analysis of valley fill overburden slope analysis. 


\section{Chapter 3}

\section{Coal Extraction Methodology}

\subsection{Mountaintop Mining Operations}

Mining in Applachia, with its steep terrain and complex geology, is not easy. Large surface mining equipment, and detailed planning is required to mine the low-sulfur reserves economically. The major mountaintop mining operations in USA are shown in Figure 3-1.

Of the mines shown in Figure 3-1, the mining methodology used at Hobet 21 mine (Arch Coal, West Virginia), is presented in Figure 3-2.

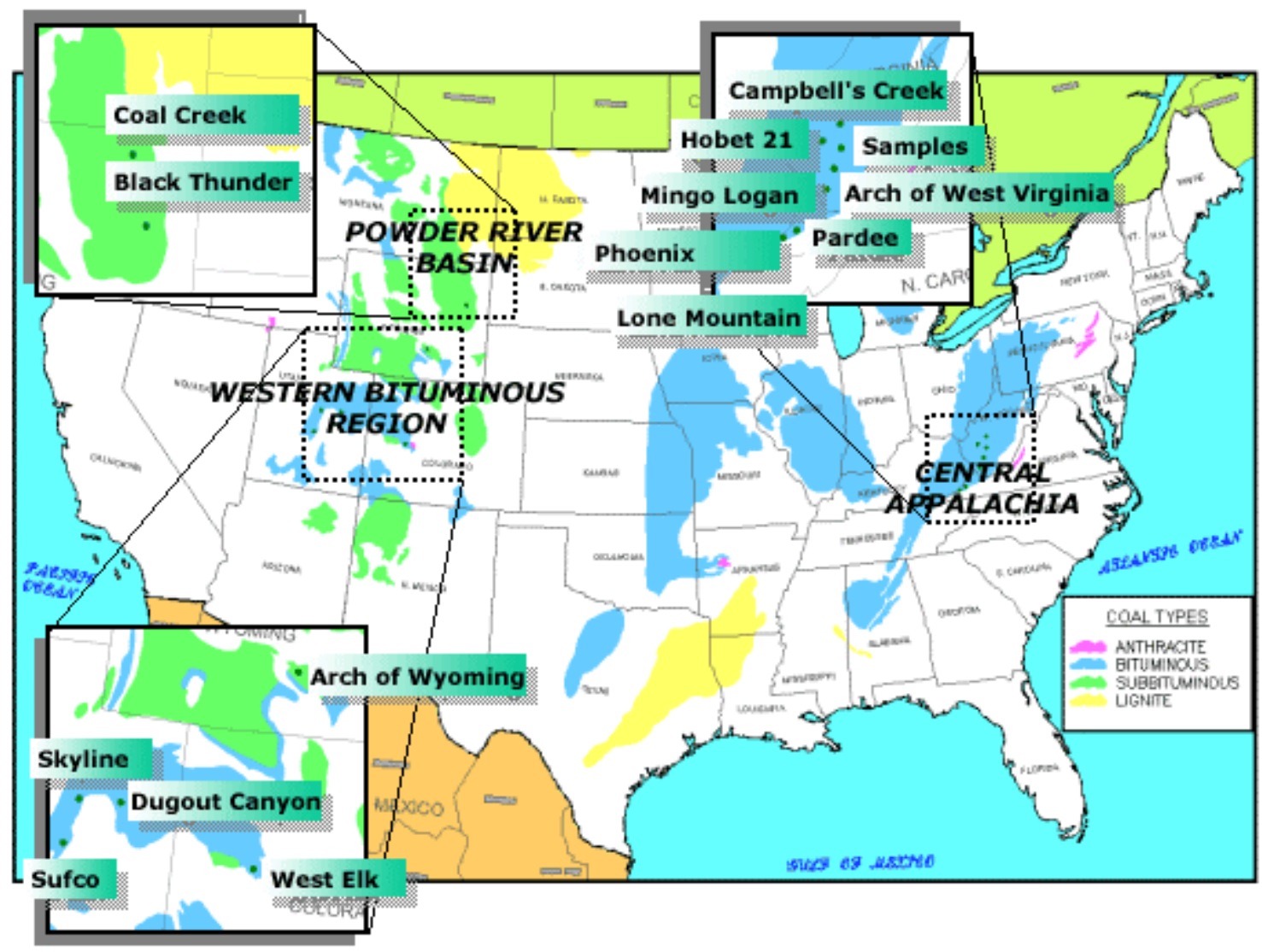




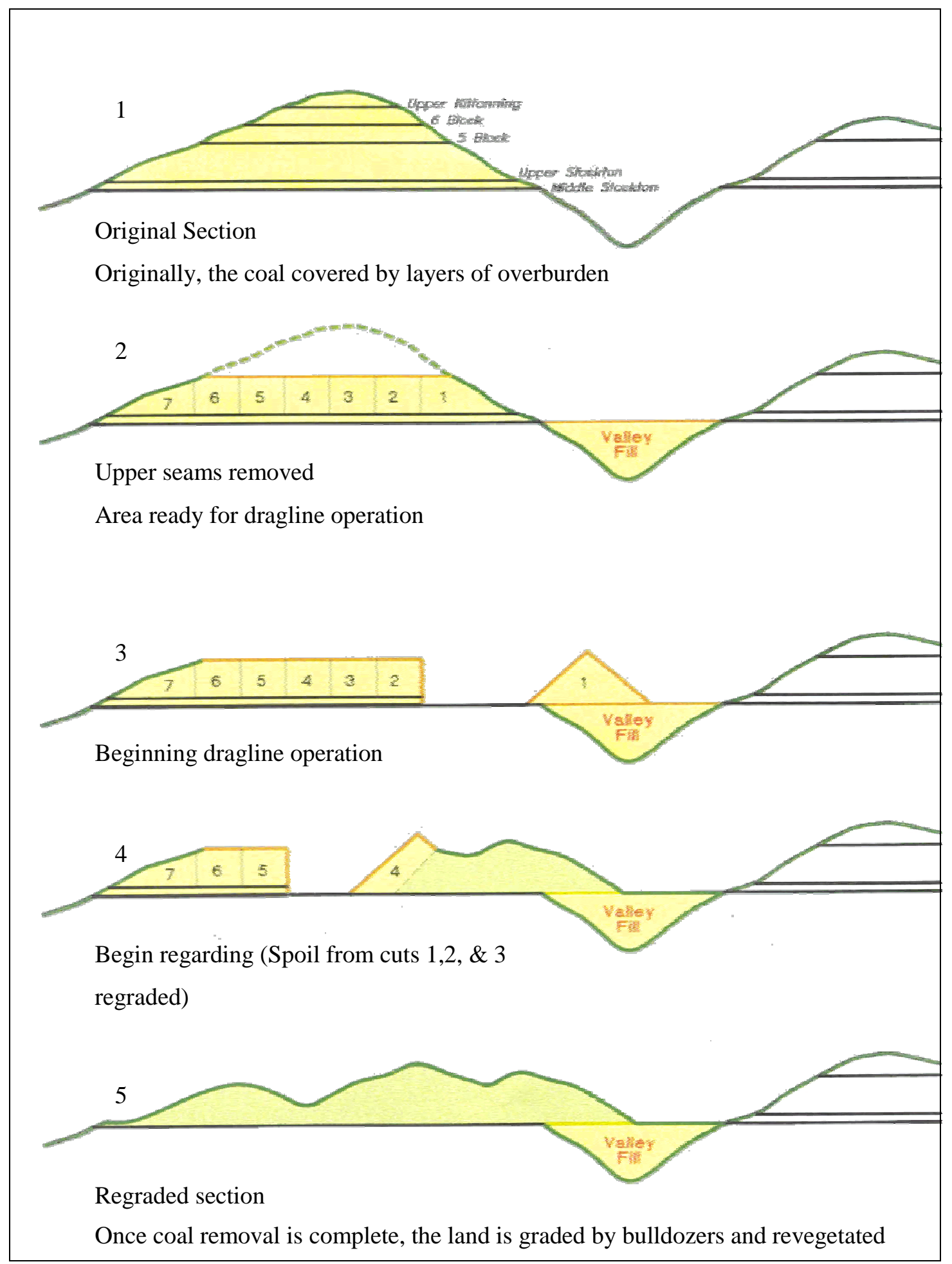

Figure 3-2: Mountaintop Mining Methodology (Source: Hobet 21 mine, Arch Coal) 
The top of the mountain is removed to uncover the most economically minable coal seams. The overburden and interburden removed are placed in valley fills and backstacked on previously mined areas as required to produce coal. Under ideal conditions it is possible to extract $100 \%$ of the minable coal, and results in the movement of more than 42 million cu-yd/year of overburden and interburden. The general sequence of mountaintop mining operations is as follows:

Phase\#1: The mining operation begins by clearing the trees from the permitted area so that wood was not commingled with the waste, as this would compromise the stability of the designed fill areas. A contour cut was then made on the lowest minable seam. This operation provided control drainage and a bench to prevent the downslope placement of material.

Phase\#2: After the contour cut is completed and the appropriate drainage is in place, prestripping for the dragline begins. Prestripping operation forms the major part of mountaintop mine development phase. After driving a contour cut on the lowest minable seam, access roads were developed to reach the top of the mountain. The initial topography of the mine permit area is shown in section 1 of Figure 3-2. The stratigraphic succession of the mine permit area is shown in Figure 2-1. The prestripping phase is shown in Figure 3-3. In the prestripping phase, the mine development was carried out in the ascending order i.e., from the lowest minable seam to the top of the mountain. The removal of overburden, interburden, and coal extraction are carried out in the descending order.

The prestripping phase is carried out continuously through out the development and production cycles of the mountaintop removal mine. In Figure 3-3, shovel loader and end dump trucks are deployed in various stages. The kind of equipment chosen to be deployed depends on the height of the overburden bench, quantity of material to be handled, 
condition of the access roads, distance of the spoil disposal site from the loading point, etc.

Prestripping is performed with shovel loaders and $284 \mathrm{~T}$ end dump trucks. Coal is removed with loaders and $218 \mathrm{~T}$ end dump trucks. In Figure 3-3, the $75 \mathrm{ft}$ spoil bench between the Upper Five block and the Kittaning seams was the dragline bench. The combination of $\mathrm{P} \& \mathrm{H} 5700$ (43 cu. yard) shovel, and five 284T end dump trucks was used to carry out the prestripping work. Partings less than $6.5 \mathrm{ft}$. thick are removed with front end loader (10 cu. yard), and 85T end dump trucks.

Phase\#3: To develop a cost-effective operation, dragline deployment has become a must. When prestripping is at least 15 months ahead of the dragline, the dragline is placed into operation. Prestripping is continued to maintain the 15-month gap with the dragline operation. Prestripping is three-shift, five-day-a-week operation, whereas the dragline is a threeshift, seven-day-a-week operation. The conceptual view of dragline deployment is shown in Figure 3-4. A $5 \mathrm{ft}$ cover of spoil was maintained over the coal seams to act as a cushioning layer, and absorb the pressure of 2000T per square inch during the dragline's frog-leap movement. The dragline advanced by $2.2 \mathrm{~m}(6.6 \mathrm{ft})$ in one leap.

The Marion 8400 walking dragline with a boom length of $104 \mathrm{~m}$ (341 ft), and a bucket capacity of $38 \mathrm{~m}^{3}$ (50 cu. yard) was used. Cast blasting was used when conditions permitted.

Phase\#4: As each coal seam was uncovered, 13.5 cu-yd front-end loaders loaded coal into $77 \mathrm{~T}$ end-dump trucks. Other spreads of frontend loaders and end-dump trucks load and haul the thinner interburden between coal splits to waste. This procedure is called split loading.

In figure 3-2, section 2 shows the post-stripping scenario, where mountain peaks are removed by an electric shovel, creating a flat surface for the dragline operation. The mining area is divided into pits for efficient removal of overburden. The overburden removed is placed in the valley fill. Section 5, 
shows the final pit configuration. The AOC variance allowed depends upon the terrain of the permit area. 


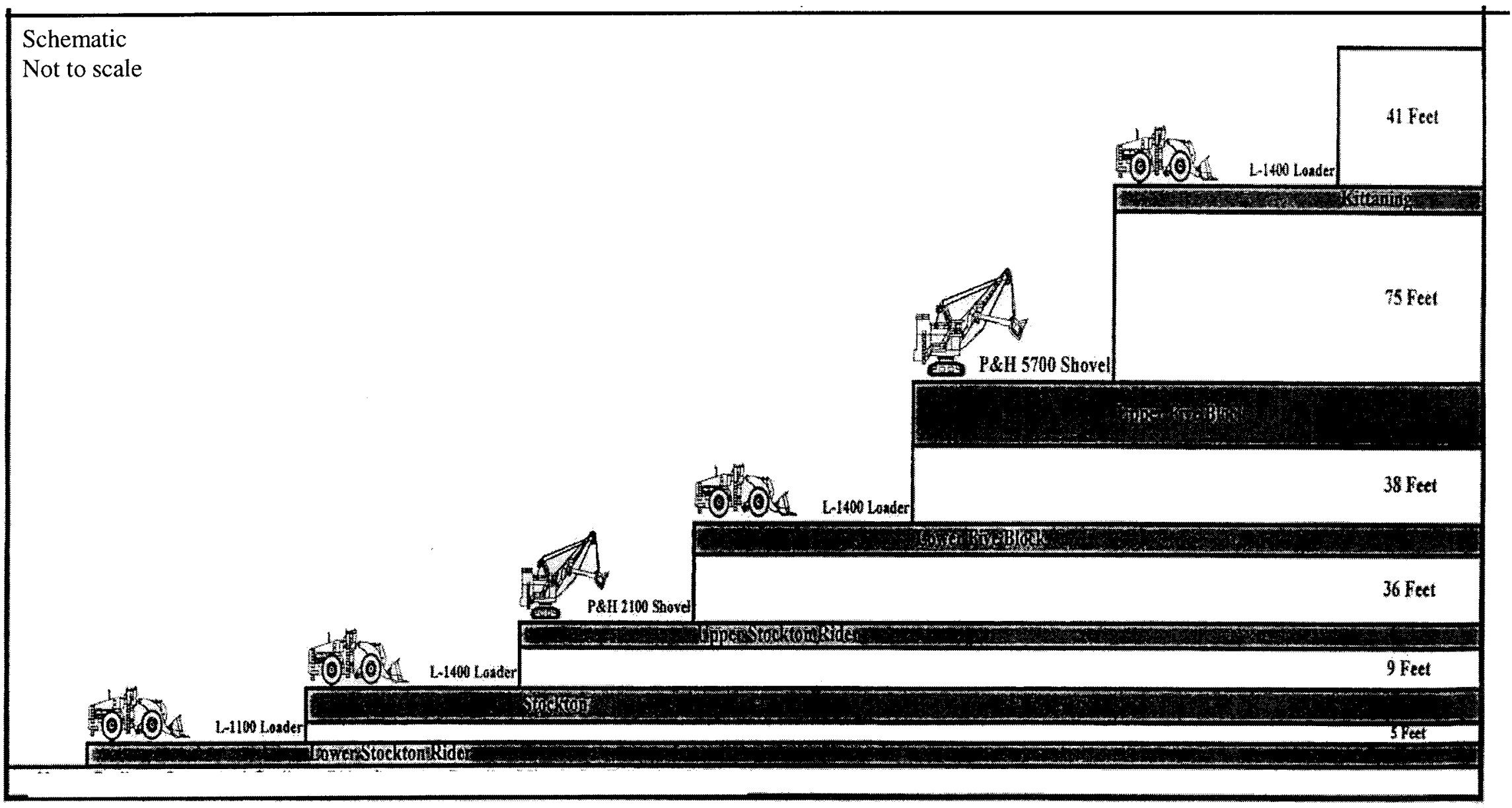

Figure 3-3: Phase\# 2 of mountaintop mining operation sequence, prestripping operation. (Source: Barata, 2000) 


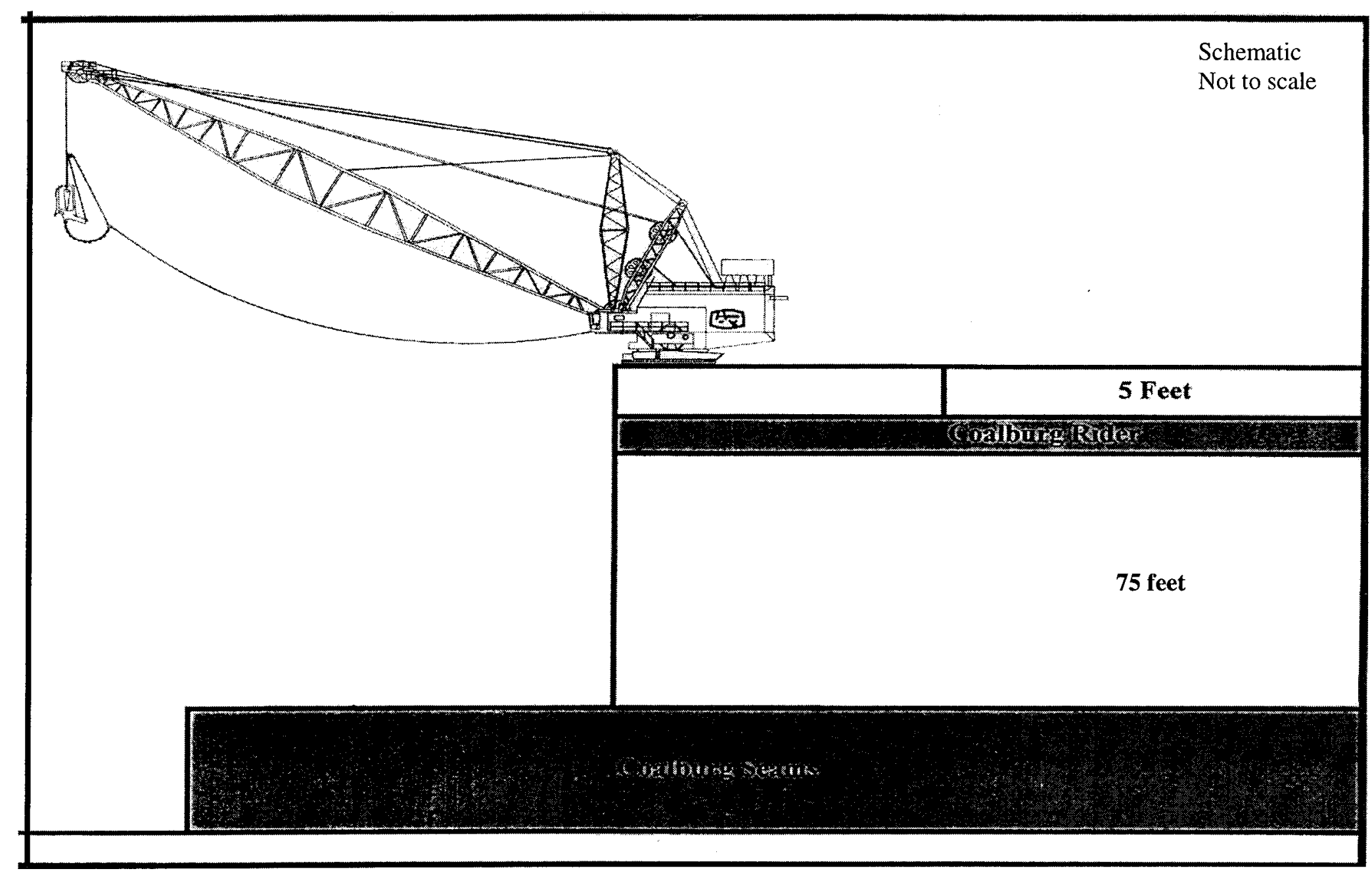

Figure 3-4: Phase \#3 of mountaintop mining operation sequence, upper seams are prestripped using shovels and loaders (see Figure 3-3) (Source: Barata, 1995) 
The selection criterion of mining equipment depends on many parameters such as geology, total spoil material to be handled, average hauling distance, average gradient of the haul roads, and slopes, variations in coal split thickness, variations in interburden thickness. The equipment in fleet is shown in Table 3-1.

Table 3-1: Equipment in Fleet in a typical mountaintop removal (MTR) mine.

\begin{tabular}{|lcl|}
\hline Equipment (type/size) & Fleet & Deployment \\
Dragline (50 cu-yd / 104m) & 1 & Phase\#3 \\
Shovel, electric (43 cu-yd) & 1 & Phase\#2 \\
Shovel, electric (38 cu-yd) & 1 & Phase\#2 \\
Shovel, electric (33 cu-yd) & 1 & Phase\#4 \\
Front-end loader (27 cu-yd) & 1 & Phase\#2 \\
Front-end loader (23 cu-yd) & 1 & Phase\#2, \& 1 \\
Front-end loader (13.5 cu-yd) & 4 & Phase\#4 \\
Front-end loader (10 cu-yd) & 2 & Phase\#4 \\
Trucks, end-dump 284 t & 10 & Phase \# 2 \\
Trucks, end-dump 284 t & 3 & Phase\#2, \& 3 \\
Trucks, end-dump 284 t & 2 & Phase\#4 \\
Trucks, end-dump 284 t & 4 & Phase\#4 \\
Dozers, Crawler < 400 hp & 3 & Phase\#1 \\
Dozers, Crawler > 400 hp & 10 & Phase\#3 \\
Drills, 10.62" & 2 & Phase\#2 \\
Drills, 7.87” & 1 & Phase\#2, \& 4 \\
Drills, 3.87” & 3 & Phase\#4 \\
\hline
\end{tabular}




\subsection{Analysis of Coal Extraction techniques}

The coal extraction methodology is tightly coupled with the spoil-handling plan. The first process in mountaintop removal (MTR) operations is to prepare a detailed plan of mining and reclamation phase to be carried out in the permit area. The amounts of excess spoil to be generated, and excess spoil handling plans should be submitted with the permit application. The first step in designing an excess spoilhandling plan is to determine the $\mathrm{AOC}$ and the excess spoil to be generated. Determination of excess spoil is done using the AOC model presented in chapter 2 (usually by the regulatory authorities).

The main objectives of any mountaintop mining methodology are:

1. Gain access to the coal seam in the minimum possible time. The gestation period of the project should be minimum.

2. Dispose the excess spoil generated (spoil over and in excess of that used for backfilling and backstacking) during mining to the nearest valley or head-of-hollow region.

3. Maintain a steady rate of coal production, and comply with the regulations on excess spoil disposal.

4. Monitor the surface configuration of the mining area with respect to returning it to $\mathrm{AOC}$, or to a pre-set $\mathrm{AOC}$ variance standard (if a $\mathrm{AOC}$ variance is granted).

5. Not to affect the wild life and aquatic resources of the permit area.

6. Finally, return the mined-out land to a pre-set post-mine land use.

Do the MTR mining firms meet the objectives mentioned above?

Phase\#3 of the MTR mining operation draws the attention of environmentalists and the public in general. A large area of land is affected in a dragline operation. In 1980s MTR mines created valley fills with spoil volume no greater than 250,000 cubic yards of rock and spoil material. Today using $240 \mathrm{~T}$ 
dump trucks and modern draglines, some valley fills have exceeded 100,000,000 cubic yards of spoil material (Charleston Gazette, 1998). In the pre-stripping phase, large expanses of land are left bare or exposed and this leads erosion, dust and other impacts.

These concerns are legitimate and need to be answered by the mining engineers. A dragline is very huge and very expensive equipment. It is the ideal machinery for moving overburden and interburden at an economical pace in a MTR mining operation. The lag in pre-striping phase is required, to provide legroom for the dragline operation. "Contemporaneous reclamation" should be carried out to minimize the degradation of the large area exposed during this phase.

The amount of spoil disposed in the adjacent valleys should not be a concern provided the fill area is not encroaching natural and perennial streams, aquatic resources and privately owned areas. Huge valley fills can be well designed and monitored for the effects of earthquakes, blasting, seepage, surface runoff etc. Valley fill slope stability issues will be discussed in chapter 4. 


\section{Chapter 4 \\ Valley Fill Slope Stability}

\subsection{Introduction}

This chapter presents an overview of the valley fills formed during MTR mining operations, and an analysis of their slope stability. The valley fill slopes are first analyzed using Bishop's and Janbu's simplified method of slices. Wong (1984) developed a probabilistic methodology for the analysis of slopes subject to circular failure. Deterministic analysis equations are used to predict either the factor of safety or critical height of slopes. These equations are structured within a Monte Carlo simulation program to perform the calculations. The output of the simulation is a probability distribution of either factor of safety or critical height. The output distribution is compared to criteria for the acceptability of risk levels for different design situations. Peterson (1999) developed a probabilistic methodology for practical analysis of slope stability. This methodology is used for the probabilistic analysis of valley fill slope stability.

The scope of work for the study includes an analysis of stability characteristics of valley fill construction techniques used in the mining and reclamation activities carried out in mountainous areas of southwestern West Virginia. The valley fills formed are some of the largest earth constructions on earth today, with a relief of $450 \mathrm{ft}$ to $600 \mathrm{ft}$ and a stretch of $500 \mathrm{ft}$ to $2000 \mathrm{ft}$. The slope angle of the fills varies from $18^{\circ}$ to $36^{\circ}$. Laboratory tests on representative materials were conducted to determine pertinent physical properties of material constituting the valley fills (Barata. 2000). Basic index properties such as grain size distribution, direct shear strength, and moisture content were measured.

\subsection{Deterministic Analysis of Valley fill slope Stability}

The slope stability analysis of three valley fills sites is carried out using XSTABL (developed by Interactive Software Design Inc., Moscow, Idaho). The geomechanical properties of the surface and subsurface layers of the valley fills are 
determined by conducting laboratory experiments on borehole samples. The surface and subsurface configurations are prepared from the data obtained by reconnaissance, and survey of the site.

\subsubsection{Site 1}

The valley fill construction was completed in October 1981, and this site is selected to study the slope stability of a long-standing valley fill. The fill is situated in a narrow valley with a relief of $525 \mathrm{ft}$. Geometrically; the fill consists of four benches and a platform. The slope angle of the benches varies from $25.8^{\circ}$ to $36^{\circ}$. The fill surface is well vegetated.

The vertical distance between benches varies from $19 \mathrm{ft}$ to $25 \mathrm{ft}$. Figure 4-1 shows the aerial view of the valley fill at site1. Figure 4-2 is a plan view sketch of the fill. Three standard test boring S1, S2, and S3 were drilled to provide data on the material comprising the fill and the underlying natural soil and bedrock. S1 and S3 were drilled on the platform and S2 was drilled in the first bench below the platform. The fill has a cover of natural soil over the competent rock. The results from the analysis of the boring soil samples of valley fill site1 are shown in Table 41 .

Table 4-1: Overburden fill thickness and Natural soil thickness from boring samples at Site1

\begin{tabular}{ccc}
\hline Boring \# & Fill thickness & Natural soil thickness \\
\hline S1 & $70 \mathrm{ft}$ & $33.5 \mathrm{ft}$ \\
S2 & $55 \mathrm{ft}$ & $33.0 \mathrm{ft}$ \\
S3 & $41 \mathrm{ft}$ & $23.5 \mathrm{ft}$ \\
\hline
\end{tabular}

The valley fill profile, soil weight and strength parameters are entered into the XSTABL program. XSTABL is a program developed by Interactive Software Design Inc., Moscow, Idaho. In this program the Simplified Bishop method and Janbu's method of slices were employed. The valley fill is placed on a coordinate system and the data for the geometric cross-section, along with the geo-mechanical properties of the various surfaces was entered into the XSTABL program. The program contains a search routine whereby it is possible to study a large number of circular failure surfaces in a short period of time. 150 critical circular failure 
surfaces were generated, and the critical circular failure surface with the least Factor of Safety (FS) was chosen as the 'most critical failure surface.'

Peizometric line is assumed based on the ground water readings. The unit weight of ground water is assumed to be 62.4 pcf. The soil properties used in the slope stability analysis of valley fill at site 1 are given in Table 4-2.

Table 4-2: Valley Fill Soil parameters at Site1.

\begin{tabular}{lll}
\hline Parameter & Spoil & $\begin{array}{l}\text { Natural } \\
\text { soil }\end{array}$ \\
\hline Unit Weight $(\gamma)$ & 124.2 pcf & 131.3 pcf \\
Angle of internal friction $(\phi)$ & $21^{0}$ & $32^{0}$ \\
Cohesion $(\mathrm{c})$ & 0.16 tsf & 0.06 tsf \\
\hline
\end{tabular}

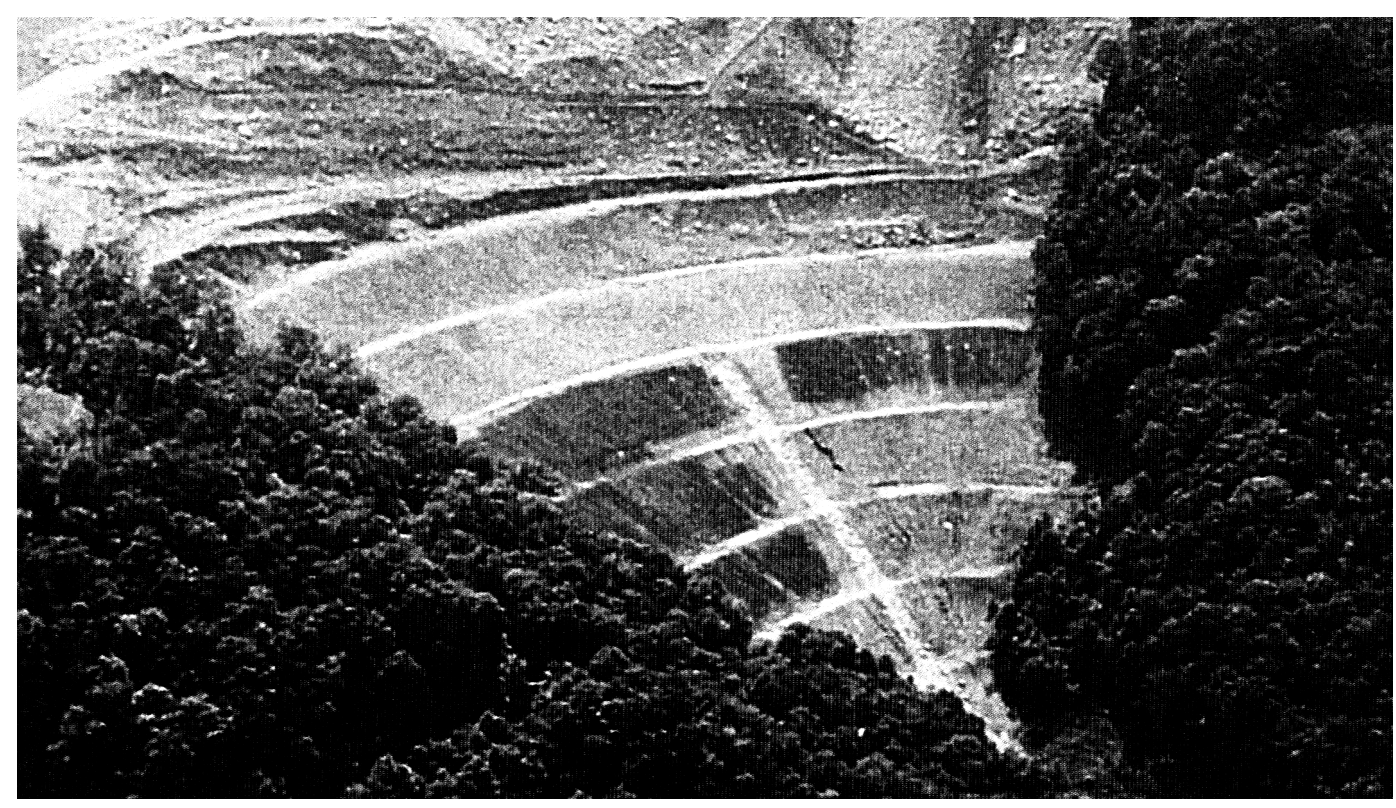

Figure 4-1: Aerial view of valley fill at site 1. 


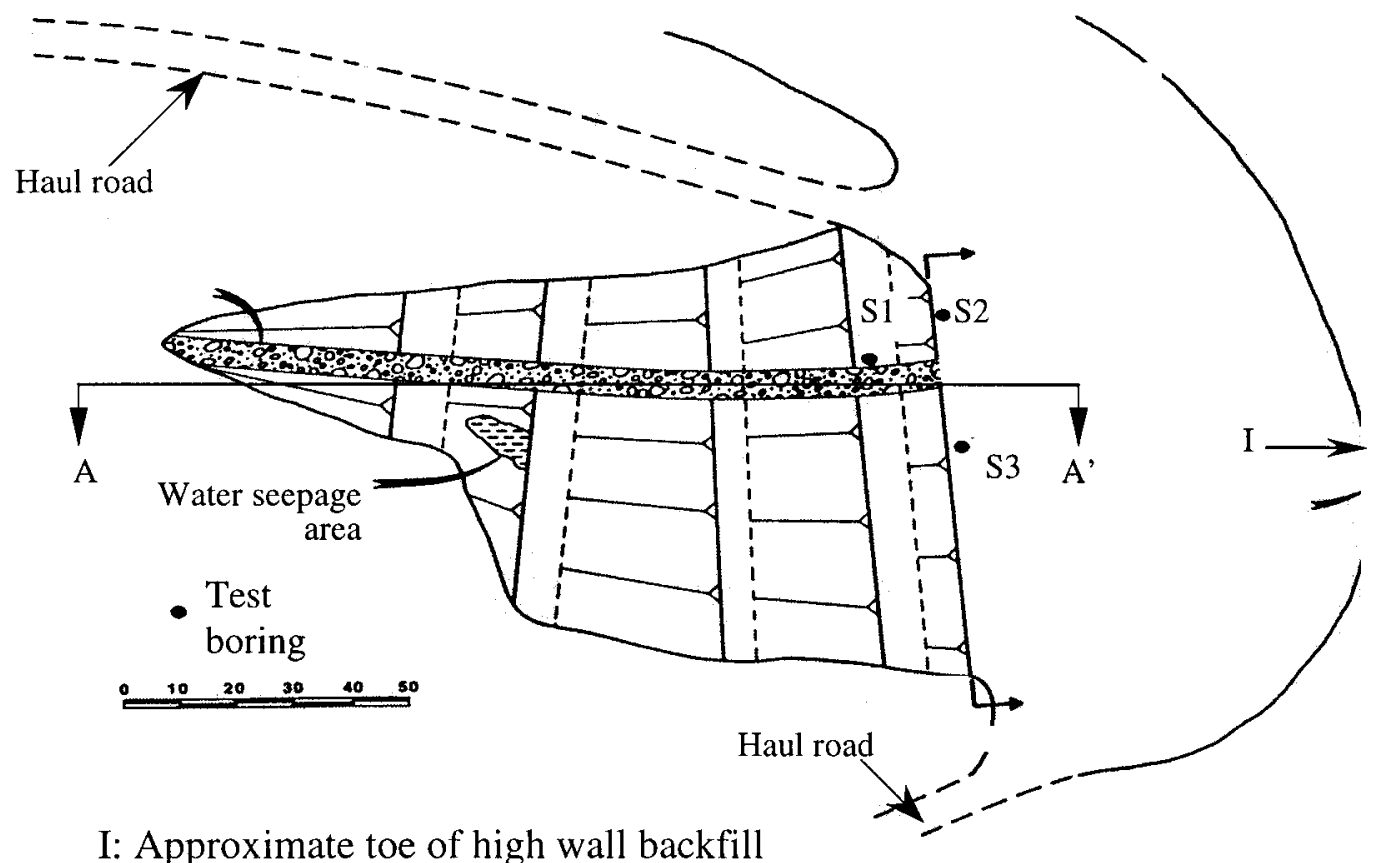

I: Approximate toe of high wall backfill

Figure 4-2: Plan of Valley Fill at Site 1.

The slope geometry at site 1 along A-A' section from Figure 4-2, is shown in Figure 4-3 and Figure 4-4. The Bishop's Simplified method of slices is shown in Figure 4-3. The Janbu's Method of Slices is shown in Figure 4-4. The outslope is steeper than the configuration laid down by the regulations, and the height of the benches does not agree with the design profile. The Bishop's minimum factor of safety (FS) was 1.26. The Janbu's minimum factor of safety [FS] was 1.28. This slope stood safe since October 1981. The lower factor of safety was for a circle passing through a lower steep bench. The remainder of the failure circles had factor of safety greater than 1.2 . 


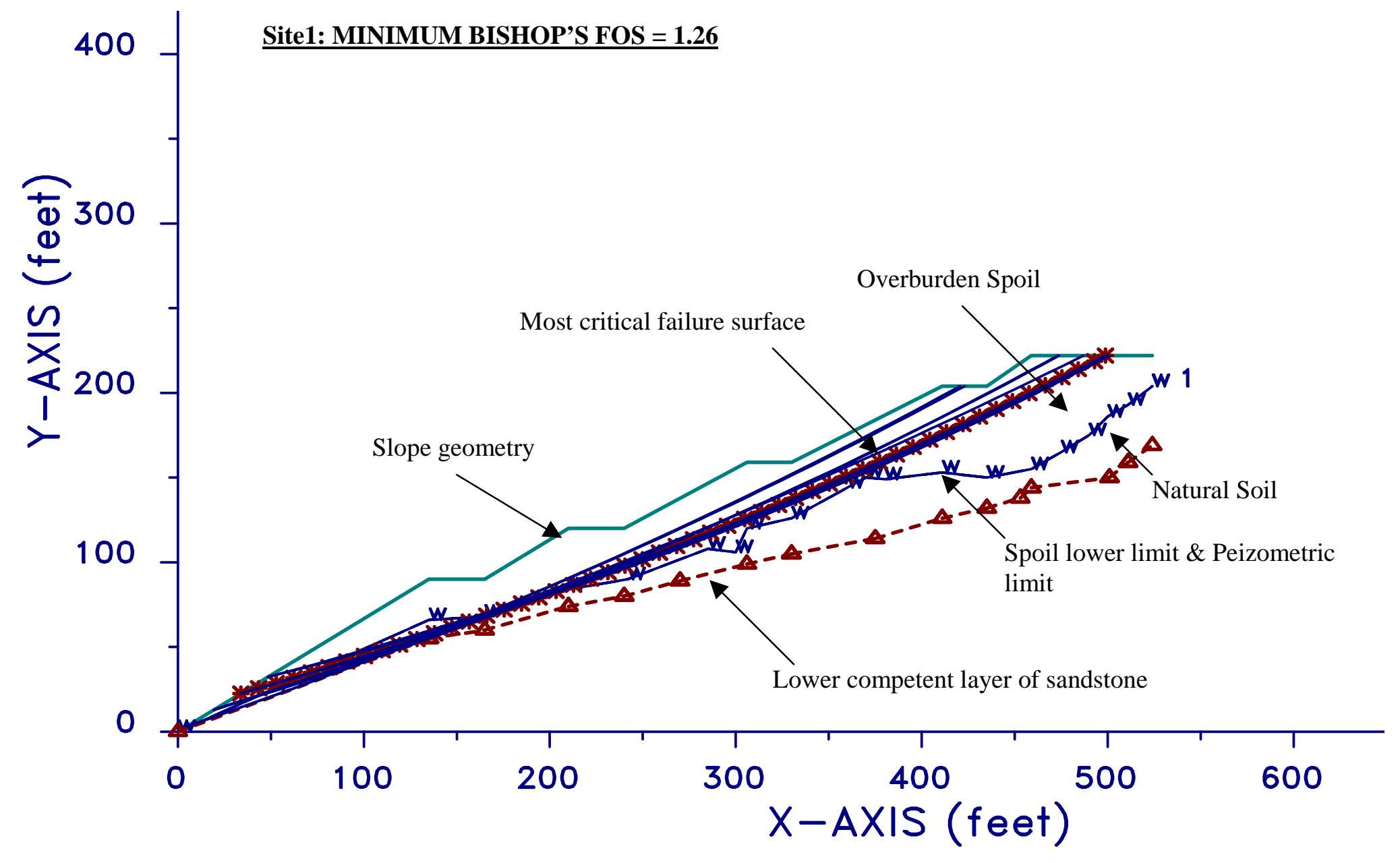

Figure 4-3: Slope stability analysis of Valley fill at Site 1, using Bishop's Simplified method of slices.

(Slope geometry along cross section A-A' of Figure 4-2). 


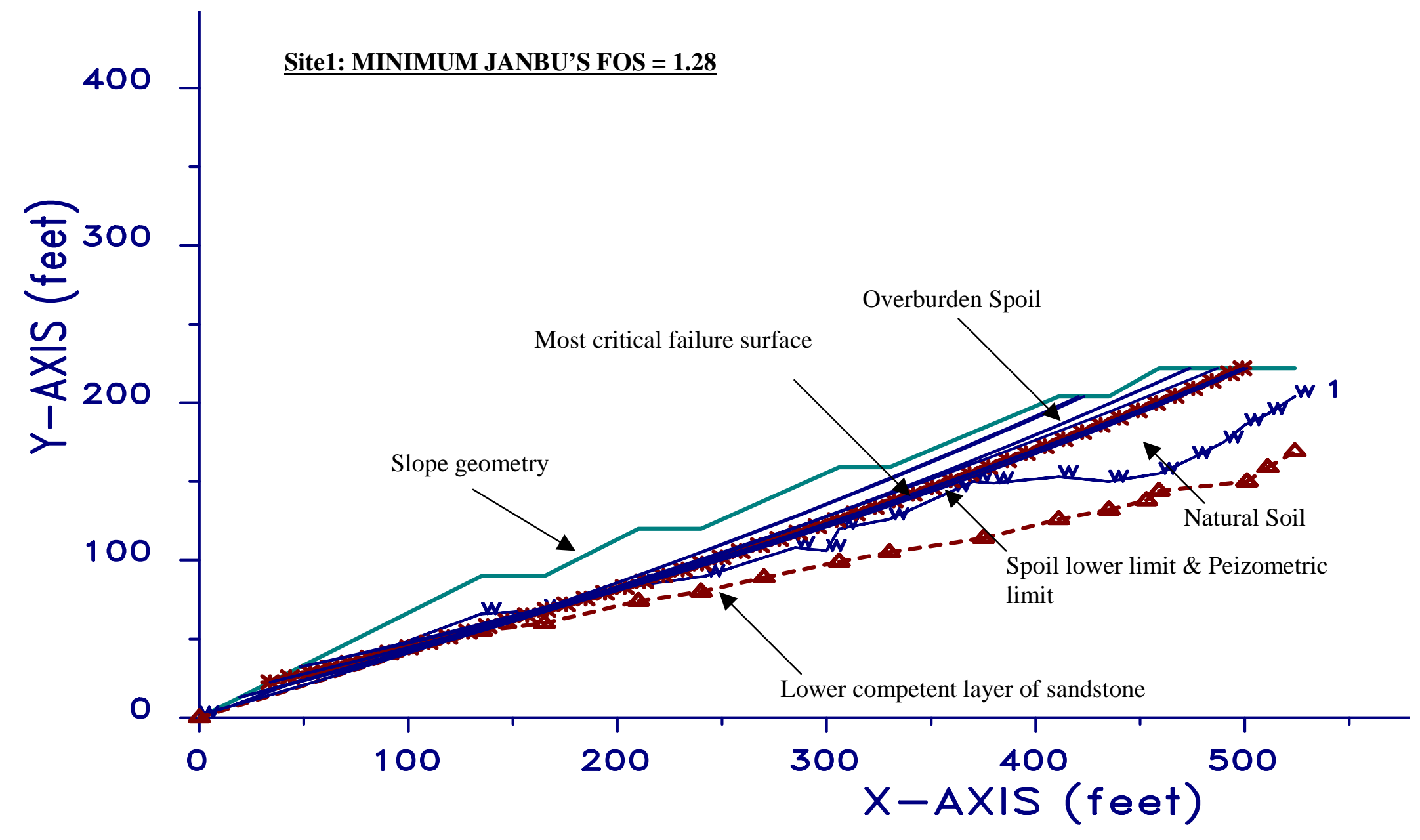

Figure 4-4: Slope stability analysis of Valley fill at Site 1, using Janbu's method of slices.

(Slope geometry along cross section A-A' of Figure 4-2). 


\subsubsection{Site 2}

The valley fill construction was completed June 1994, and this site is selected to study the slope stability of a pure spoil slope, with no under cover of natural soil over the competent lower layer. Geometrically, the fill consists of five benches and a platform. The slope angles of the benches are less than $25.8^{\circ}$. The height between benches is $40 \mathrm{ft}$ or less. The fill surface is well vegetated. Figure 4-4 shows the profile of the fill.

The zone between the backfilled highwall and the natural terrain is more exposed in this case. Three standard test borings Ss1, Ss2, and Ss3 were drilled to provide data on the material comprising the fill and the underlying natural soil and bedrock. The soil properties used for the spoil in the slope stability analysis of valley fill at site 2 are: $\gamma=124.2 \mathrm{pcf}, \phi=21^{\circ}, \mathrm{c}=0.16 \mathrm{tsf}$. No peizometric line is used in this case. The site is assumed to be fully drained.

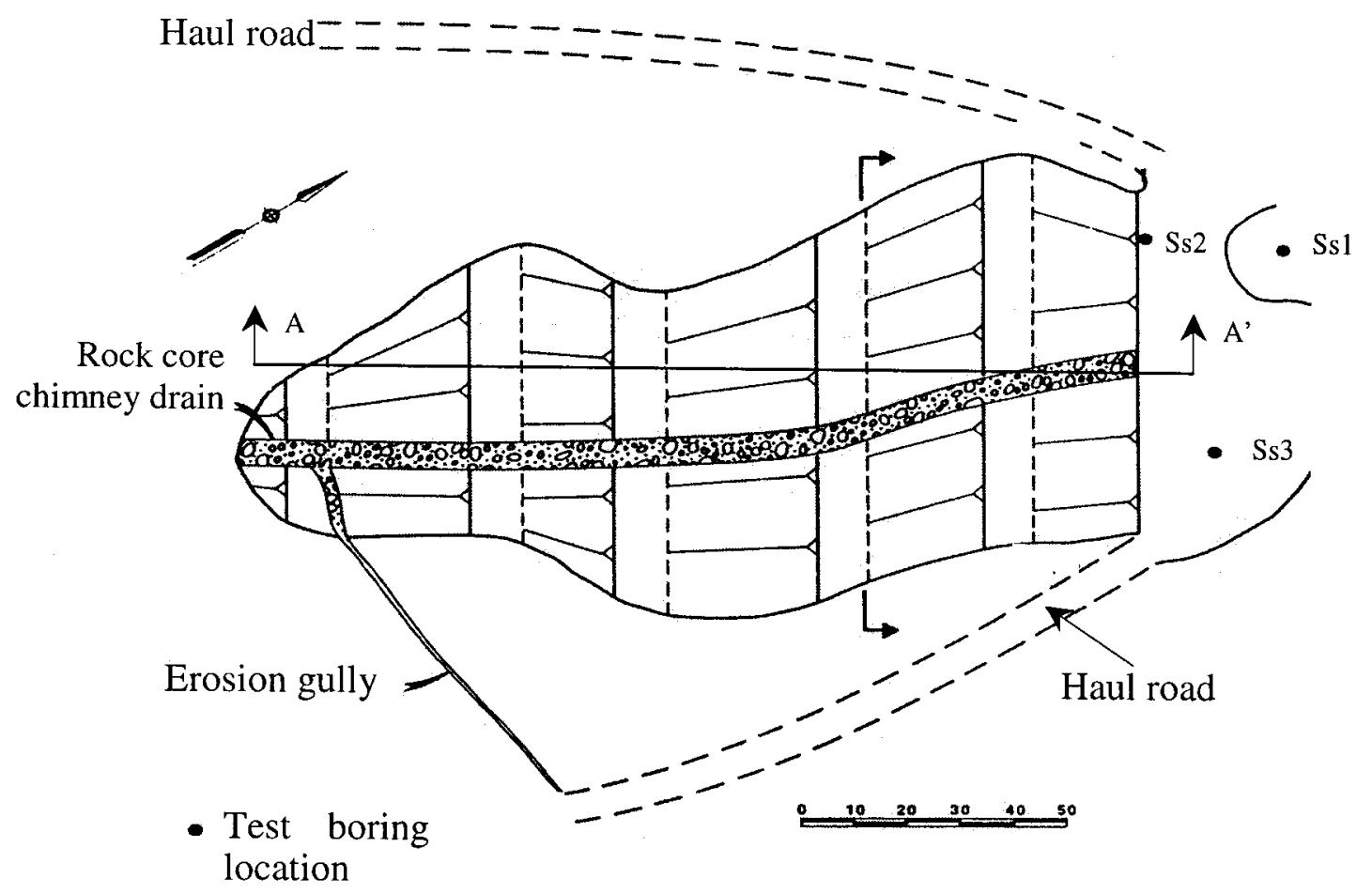

Figure 4-5: Plan of Valley Fill at Site 2. 


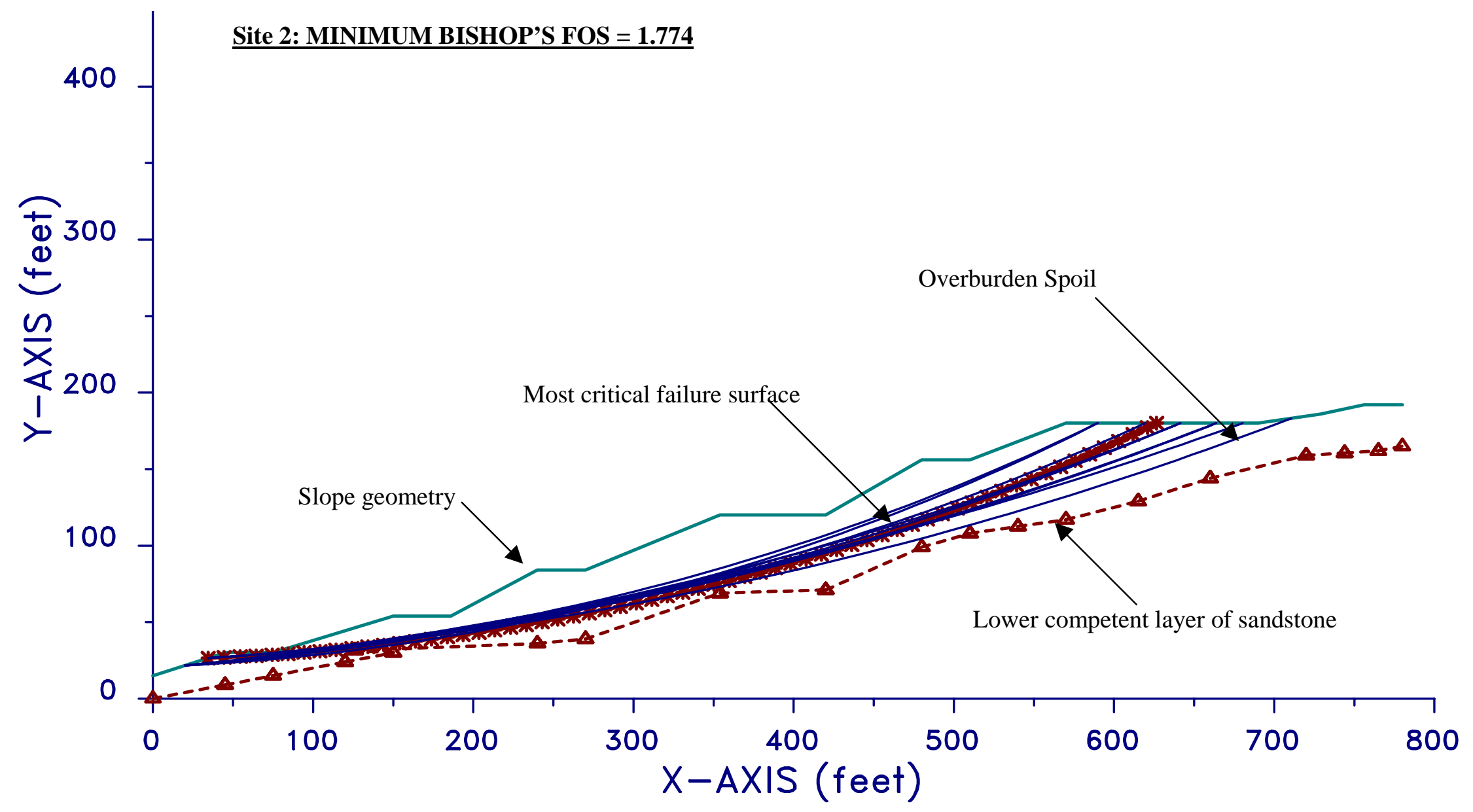

Figure 4-6: Slope stability analysis of Valley fill at Site 2, using Bishop's Simplified method of slices.

(Slope geometry along cross section A-A' of Figure 4-5). 


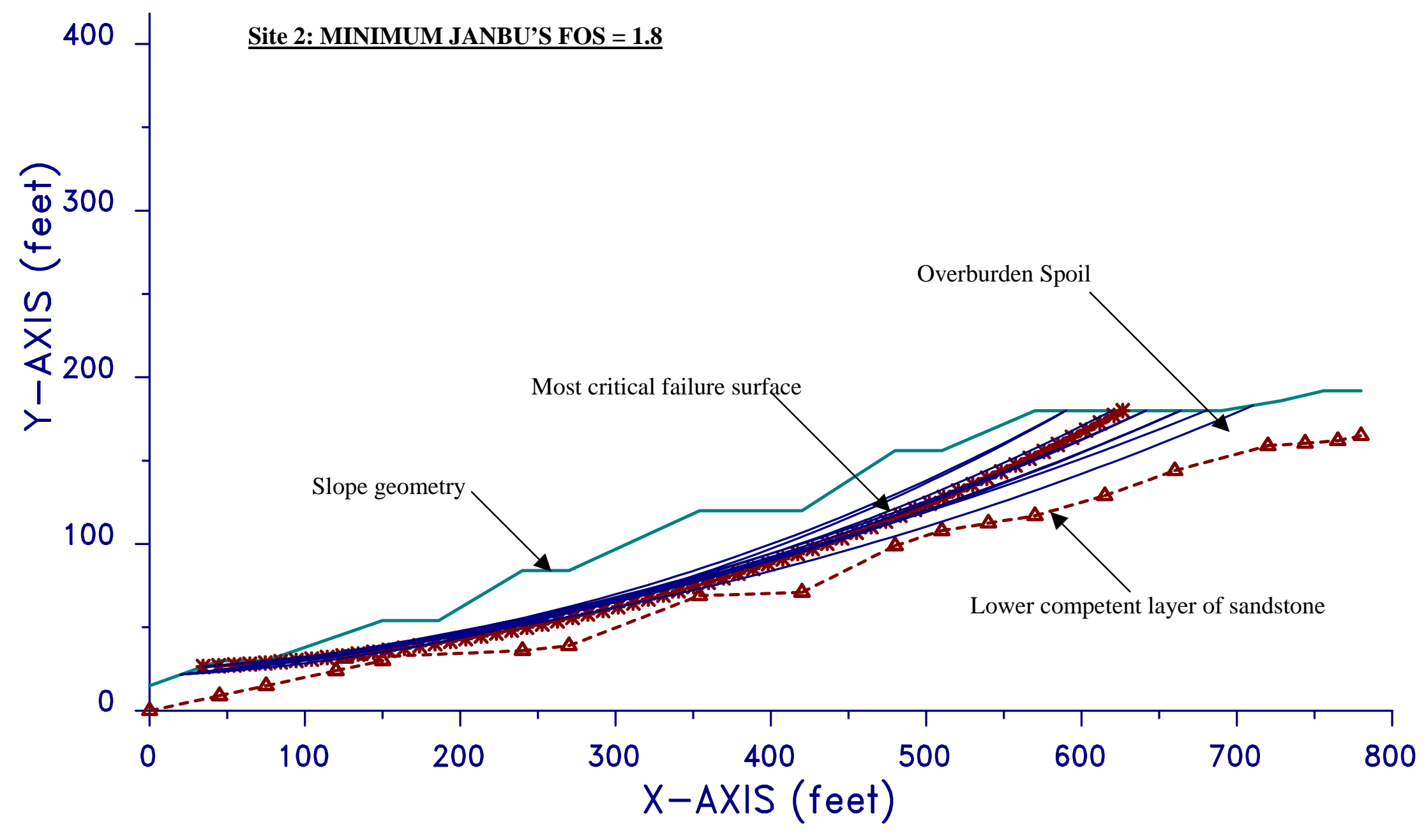

Figure 4-7: Slope stability analysis of Valley fill at Site 2, using Janbu's method of slices.

(Slope geometry along cross section A-A' of Figure 4-5). 
The slope geometry at site 2 along A-A' section from Figure 4-5, is shown in Figure 4-6 and Figure 4-7. The Bishop's Simplified method of slices is shown in Figure 46. The Janbu's Method of Slices is shown in Figure 4-7. The Bishop's minimum factor of safety (FS) was 1.77. The Janbu's minimum factor of safety (FS) was 1.8. The factor of safety of the slope is greater than 1.5, and is safe. The slope will not fail due to configuration; the effects of seepage and surface run off need to be studied.

\subsubsection{Site 3}

The valley fill construction was completed August1997, and this site is selected to study the slope stability of a valley fill slope, with low relief and greater stretch. Geometrically, the fill consists of one bench and a platform. The slope angle of the slope is less than $25^{\circ}$. The fill surface is well vegetated. Site 3 is a contour mining site where valley fills were utilized for spoil disposal. This site has a relief of $100 \mathrm{ft}$ only, but has a stretch of $2000 \mathrm{ft}$.

The slope was graded as necessary as additional fill was placed in order to comply with regulations in existence at the time of construction. There was no internal drainage system. The classification test data show a wide range in particle sizes. There are large rock fragments as well as silt and clay. The natural soil thickness varied from $6 \mathrm{ft}$ to $25 \mathrm{ft}$. The peizometric line was assumed based on the ground water readings. The unit of ground water is assumed to be 62.4 pcf. The soil properties used in the slope stability analysis of valley fill at site 3 are shown in Table 4-3.

Table 4-3: Valley Fill Soil parameters at Site 3.

\begin{tabular}{lll}
\hline Parameter & Spoil & Natural soil \\
\hline Unit weight of material $(\gamma)$ & $131.6 \mathrm{pcf}$ & $131.3 \mathrm{pcf}$ \\
Angle of internal friction $(\phi)$ & $27.5^{0}$ & $39^{0}$ \\
Cohesion $(\mathrm{c})$ & $0.19 \mathrm{tsf}$ & $0.16 \mathrm{tsf}$ \\
\hline
\end{tabular}


The slope geometry used at site 3 is shown in Figure 4-8 and Figure 4-9. The outslope configuration confirms to the regulations, and the angle of the slope does agree with the design profile. The Bishop's minimum factor of safety (FS) was 2.92 . The Janbu's minimum factor of safety (FS) was 2.97. The factor of safety of the slope is greater than 1.5 , and is safe due to configuration. 


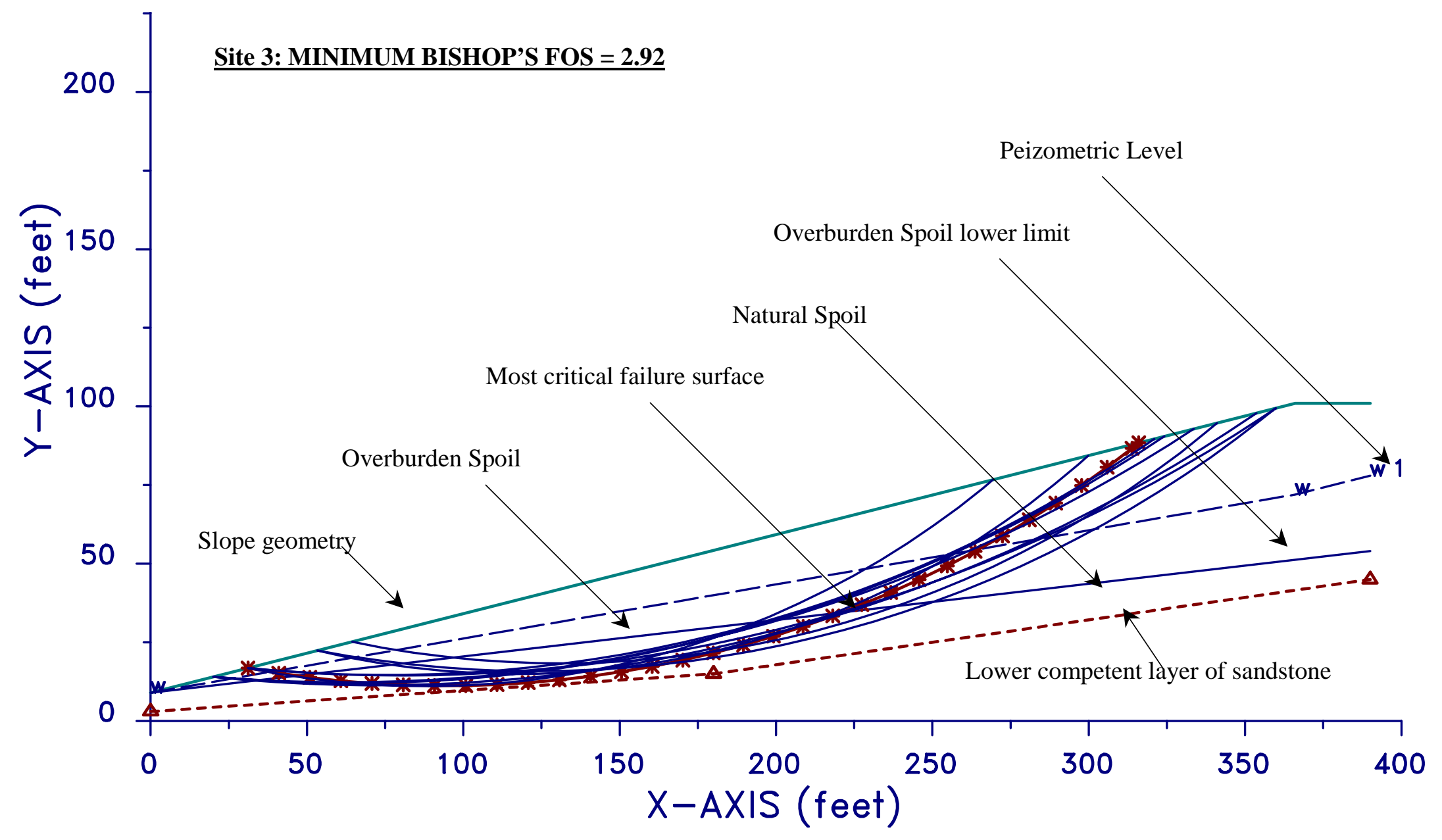

Figure 4-8: Slope stability analysis of Valley fill at Site 3, using Bishop's Simplified method of slices. 


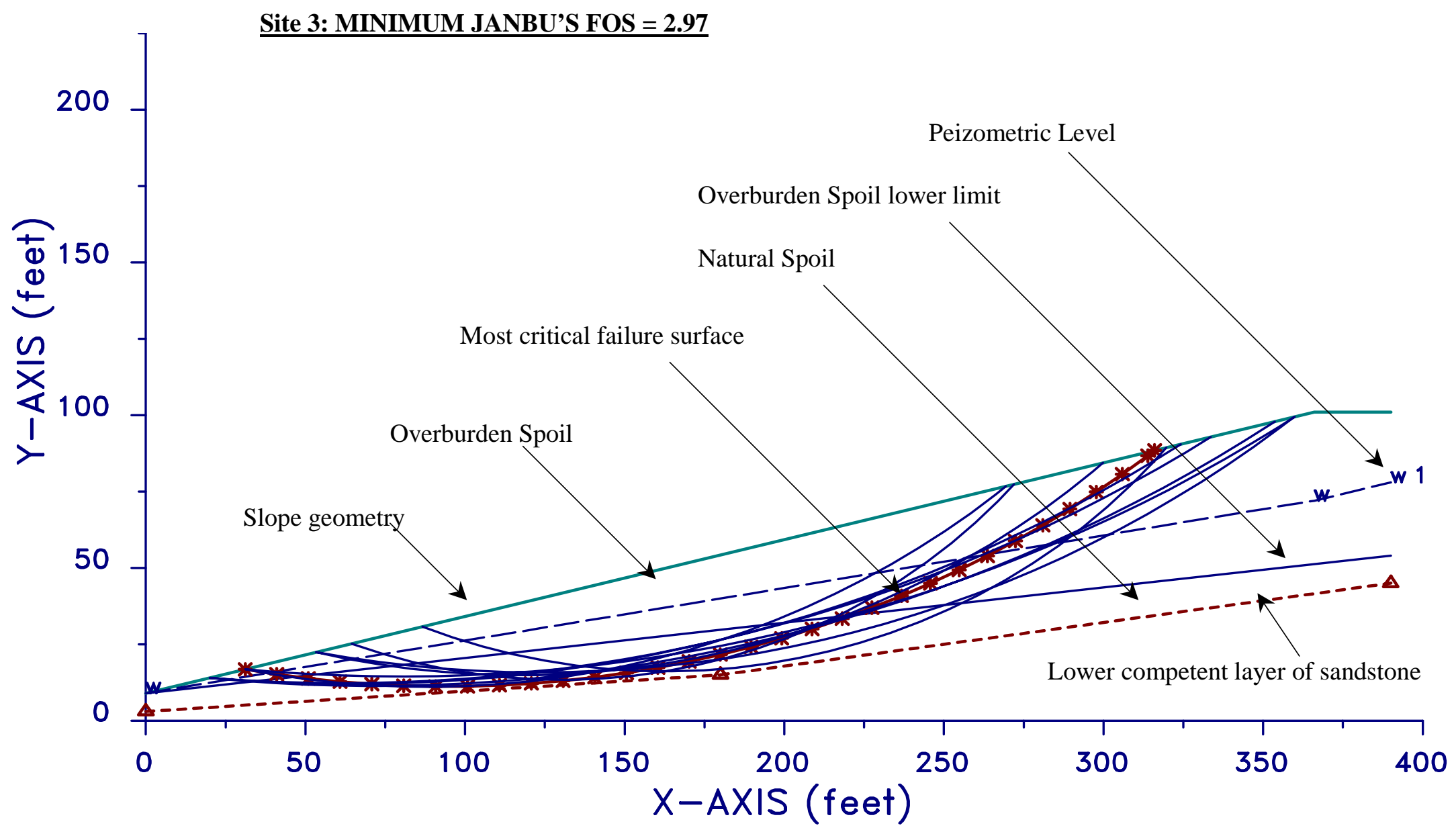

Figure 4-9: Slope stability analysis of Valley fill at Site 3, using Janbu's method of slices. 


\subsection{Probabilistic Analysis}

Probabilistic analysis of finite slope with a circular failure surface, Bishop's method, requires iterative solutions. Realistic statistical assessment of slope performance amid uncertainties requires accurate modeling of the slope mechanics, as well as the uncertainties involved. The Response Surface Method (RSM), developed by Wong (1985) is selected as a tool to overcome the incompatibilities between Bishop's method of slices used so far, and Monte Carlo simulation. For a given slope and soil unit weight, four combinations of cohesion and angle of internal friction were selected to represent the extreme cases. XSTABL is used to determine the factor of safety in each case. Graduating functions are developed systematically to provide computationally efficient statistical approximations to a long-running model. These graduating functions establish the "response surface" of the Bishop's method for this analytical situation. A response surface is based on a 2-factor, 2-level factorial design, i.e., for each of the two major parameters (cohesion and angle of internal friction) an upper limit and lower limit, $\mu-\sigma$ and $\mu+\sigma$, are used to define the region of interest. Here, $\mu$ denotes the mean, and $\sigma$ the standard deviation. A regression equation was developed from the output obtained from XSTABL. The form of regression model was:

$F S=a+a c+a_{2} \phi+a_{3} c \phi$

Equation 4-1

Where:

$$
\begin{aligned}
& \mathrm{FS}=\text { Factor of Safety } . \\
& \mathrm{c}=\text { Cohesion } . \\
& \phi=\text { Angle of internal friction } . \\
& \mathrm{a}_{\mathrm{n}}=\text { Regression constant } .
\end{aligned}
$$

The validity of the model was verified by comparing a midpoint Bishop's method analysis with the prediction from the regression equation. This regression equation was then used as a deterministic equation for use in the Monte Carlo Simulation. 


\subsubsection{Input Parameters}

The input parameters for a Monte Carlo simulation fall into two categories, the deterministic parameters used for a conventional analysis and the parameters, which define the distribution of the input variables. For slope stability analysis the deterministic parameters are:

1. Factor of Safety (FS)

2. Slope angle from the horizontal ( $\beta$ )

3. Angle of internal friction $(\phi]$

4. Cohesion ( c )

5. Unit weight $(\gamma)$

6. Saturated unit weight $\left(\gamma_{\text {sat }}\right)$

7. Submerged unit weight $\left(\gamma^{\prime}\right)$

For each of these parameters, Monte Carlo simulation requires definition of the descriptive statistics, which define the parameters' distribution. Depending on the type of distribution, the descriptive statistics may include:

1. Maximum.

2. Mean.

3. Minimum.

4. Standard deviation.

5. Coefficient of Variation.

Program Evaluation and Review Technique, PERT, was selected to model the input parameter distributions for the case studies. The PERT distribution is defined by the minimum, maximum, and the most likely (mean) values of the data. When the most likely value is the midpoint between the minimums ad maximums, the PERT distribution is symmetrical and resembles a normal distribution. During the Monte Carlo simulation, the values for each of the input parameters in the analytical equations are determined by sampling from their respective distributions. However, 
this process assumes that the input parameters are uncorrelated, as shown in Figure 4-10. In many cases, once a soil type is identified, the soil parameters are correlated, e.g., for a specific type of clay, the cohesion and angle of internal friction are correlated with the unit weight. In this case, sampling from the distributions for each parameter would produce a resulting cumulative distribution with an excessively large variance. The correct procedure for correlated input parameters is shown in Figure 4-11. In this case, the value of one parameter is determined by sampling its distribution. The values for the other parameters are estimated from correlation equations.

\subsubsection{Simulation Process}

The Monte Carlo simulation was developed within a Microsoft Excel worksheet using the @RISK add in program. The worksheet contains all input parameters and their specified distribution functions. Both the input and output data range cells need to be specified within the worksheet before the @RISK program is executed.

During the simulation process, the established model within the Excel worksheet is repetitively calculated. The statistical program, @RISK, randomly generated the selected value from the input parameter probability distributions. The required input values are determined during the simulation based on Latin Hypercubic sampling. The number of iterations to determine the output distribution is dependent on the complexity of the model and the specified distribution. Literature presented by Hutchinson \& Bandalos (1997) indicated a range of 10,000 to 100,000 iterations is necessary during a Monte Carlo simulation to obtain precise results. The specific number of iterations for slope stability models is unknown. Therefore the auto converge monitoring feature of @RISK was used to terminate the simulation. Auto converge monitoring allows the simulation to continue until three statistical parameters, mean, standard deviation, and average percent change in percentile values, converge to less than 1.5 percent. Convergence is monitored every 100 iterations during the simulation. 
Uncorrelated Parameters Input Distribution

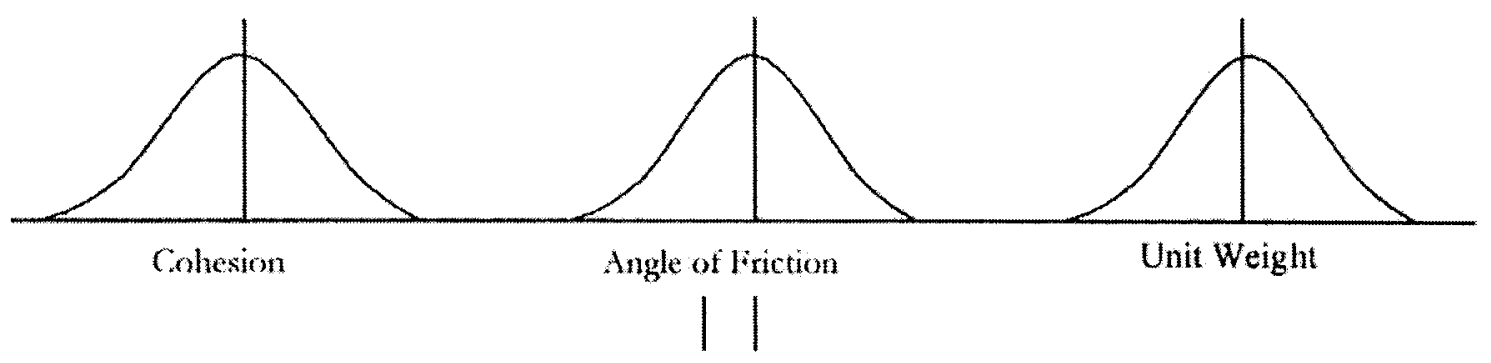

Slope Stability Analysis Method

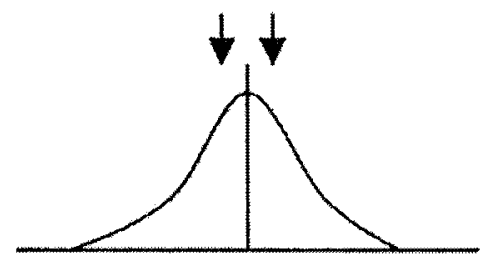

Output Distribution

Figure 4-10: Combination of Uncorrelated Input Parameters Distribution (Source: Peterson, 1999)

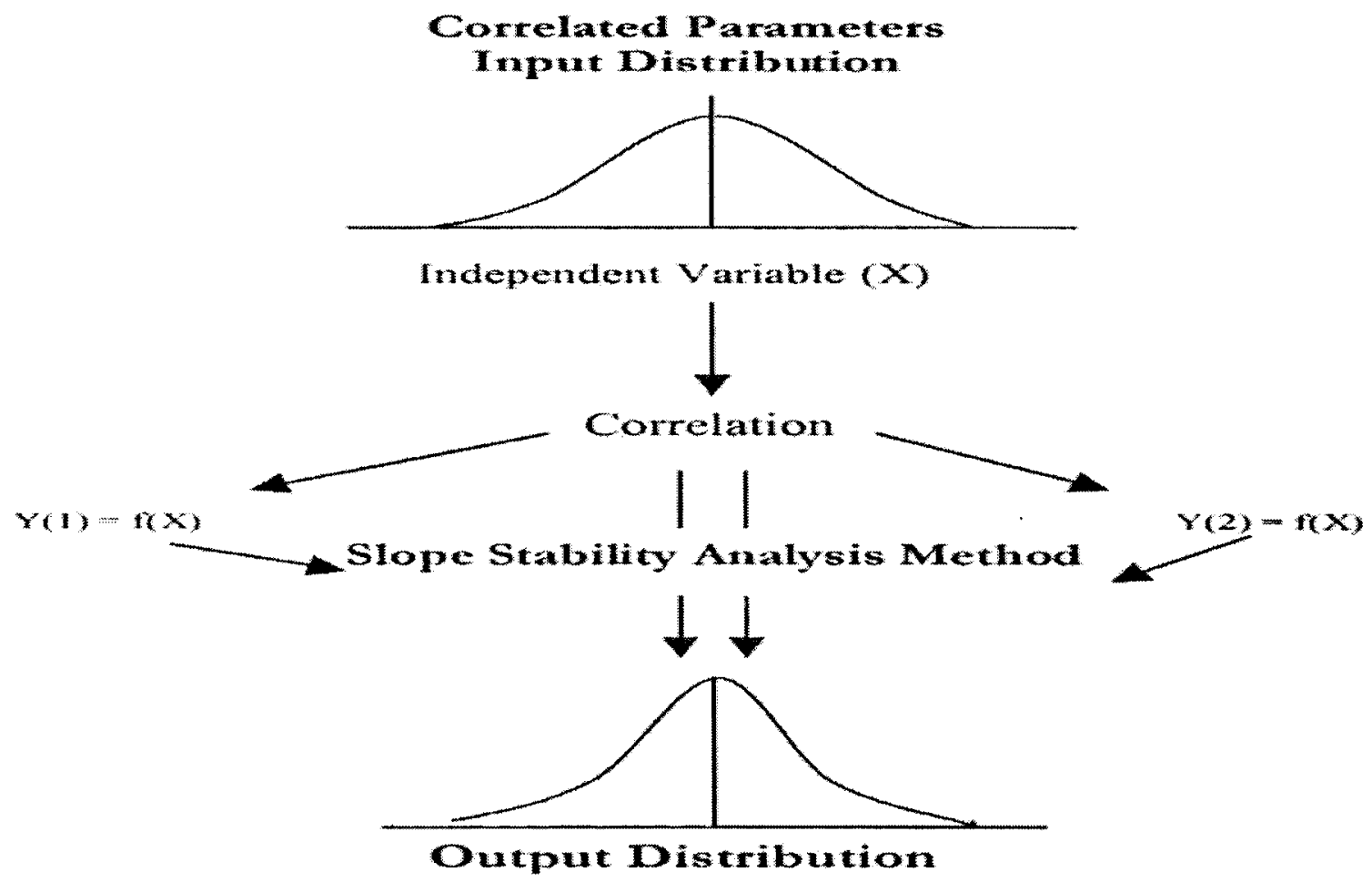

Figure 4-11: Combination of Correlated Input Parameters Distribution. (Source: Peterson, 1999) 


\subsubsection{Interpretation of Monte Carlo Simulation}

The approach used to examine the output from the Monte Carlo simulation encompasses three functions:

1. Evaluation of the sensitivity of the Monte Carlo simulation output to input parameter distributions,

2. Evaluate Monte Carlo simulation output distribution for normality using the chi-square test, and

3. Evaluation of the utility of the Monte Carlo simulation analysis for geotechnical design and analysis of slope.

The sensitivity analysis demonstrates the selective influence of the input parameters on the output of the Monte Carlo simulation. Knowledge of this information is beneficial during a geotechnical investigation; greater emphasis should be placed on the most sensitive variables. Two types of sensitivity analysis, correlation and regression, were preformed to determine the significance of the input distribution on the development of the output distribution.

\subsubsection{Methodology Application.}

The probabilistic methodology presented was used to take in account the variance in the input parameters in the circular failure surface analysis of valley fill slopes. The modified Bishop's method of slices is the preferred method for analyzing circular failure surfaces. Since the method requires an iterative solution method, it is not compatible with Monte Carlo simulation. Thus, the response surface method (RSM) was used to develop a predictive equation that can be used in the Monte Carlo simulation. The RSM method is used to develop a graduating function, which represents an output pattern, similar to the output pattern from Bishop method of slices. Using the response surface method, a graduating function can be established to account for the variance in the input parameters of only one soil unit (surface layer) of the slope. Of the valley fill sites Site 1, Site 2, and Site 3, analyzed using the deterministic methodology, the slope at Site 2 is composed of 
one surface layer over the lower competent layer. So, probabilistic analysis using the response surface method can be applied to the valley fill at site 2 only.

\subsubsection{Site 2}

The RSM method was evaluated using XSTABL to obtain the FS in four extreme input parameter cases based on the established range of data. For the analysis, the following input parameters were held constant, the horizontal angle of the slope $(\beta]=25.8^{\circ}$, unit weight $[\gamma]=124.2$ pcf.

The input parameters and the resulting FS from the XSTABL evaluation are summarized in Table 4-4. Multi-variant regression analysis is carried using Analyze-it add-in software to MS-EXCEL to fit the input data to a planar equation, which produces the output data. A normalized standard regression coefficient was determined for each input variable distribution. A standard regression coefficient associated with each input distribution ranges from -1 to +1 , where zero indicates no significant relationship between the input and output distributions. A standard regression coefficient of one indicated there is a one standard deviation change in the output distribution for a one standard deviation change in the input distributions.

Table 4-4: XSTABL evaluation of response surface analysis.

\begin{tabular}{|l|c|c|c|}
\hline Input Parameter Combination & $\begin{array}{c}\text { Cohesion } \\
(\mathbf{p s f})\end{array}$ & $\begin{array}{c}\text { Angel of internal } \\
\text { friction (degrees) }\end{array}$ & $\begin{array}{c}\text { Factor of safety } \\
(\text { FS) }\end{array}$ \\
\hline Most Favorable (+, +) & 320 & 21 & 1.774 \\
\hline Least favorable (-, -) & 299 & 17.3 & 1.489 \\
\hline Most, and Least Favorable (+, -) & 320 & 17.3 & 1.516 \\
\hline Least, and Most Favorable (-, +) & 299 & 21 & 1.748 \\
\hline Mid Point & 309.5 & 19.15 & 1.63 \\
\hline
\end{tabular}


The following graduating function was established to represent Bishop's simplified method for calculating Factor of safety (FS) of the slope:

$\mathrm{FS}=-0.1734+0.0015 \mathrm{c}+0.0738 \phi+0.000001 \mathrm{c} \phi$

Equation 4-2

Where c: cohesion, and $\phi$ : angle of internal friction

A midpoint analysis was used to verify the developed regression equation for the response surface. Based on the results of the regression equation, using the midpoint input parameters, the factor of safety equaled 1.709, which is approximately equal to the factor of safety determined from the XSTABL evaluation of 1.774. Therefore, the regression equation represents a deterministic relationship for a circular slope failure and can be used for the Monte Carlo simulation.

The distribution for the input parameter: cohesion ( c ) is shown is Figure 412. The PERT distribution has a mean $\mu=309.5 \mathrm{psf}$ and a standard deviation $\sigma=$ 3.96 psf. The distribution for the factor of safety for a circular slope failure was computed using random parameters for the angle of internal friction and cohesion to mimic the study conducted by Wong (1984). The analysis was repeated two times to evaluate the repeatability of the analysis. The distribution for input parameter: angle of internal friction $(\phi)$ is shown in Figure 4-13. The Pert distribution has a mean $\mu=19.5^{\circ}$, and a standard deviation $\sigma=0.699^{\circ}$.

The model required between 200 and 600 iterations to converge on the criteria that the computed factor of safety change less than 1.5 percent for the parameters: mean, standard deviation, and $95^{\text {th }}$ percentile. The convergence was checked after every 100 iterations.

The distribution of the computed factor of safety for each of the analysis run is shown in Figure 4-14 and Figure 4-15. The factor of safety distribution for each replicated analysis were statistically compared, verifying there was not enough difference in the distributions to statistically indicate a difference between the outputs of the replicated runs for each slope angle. 


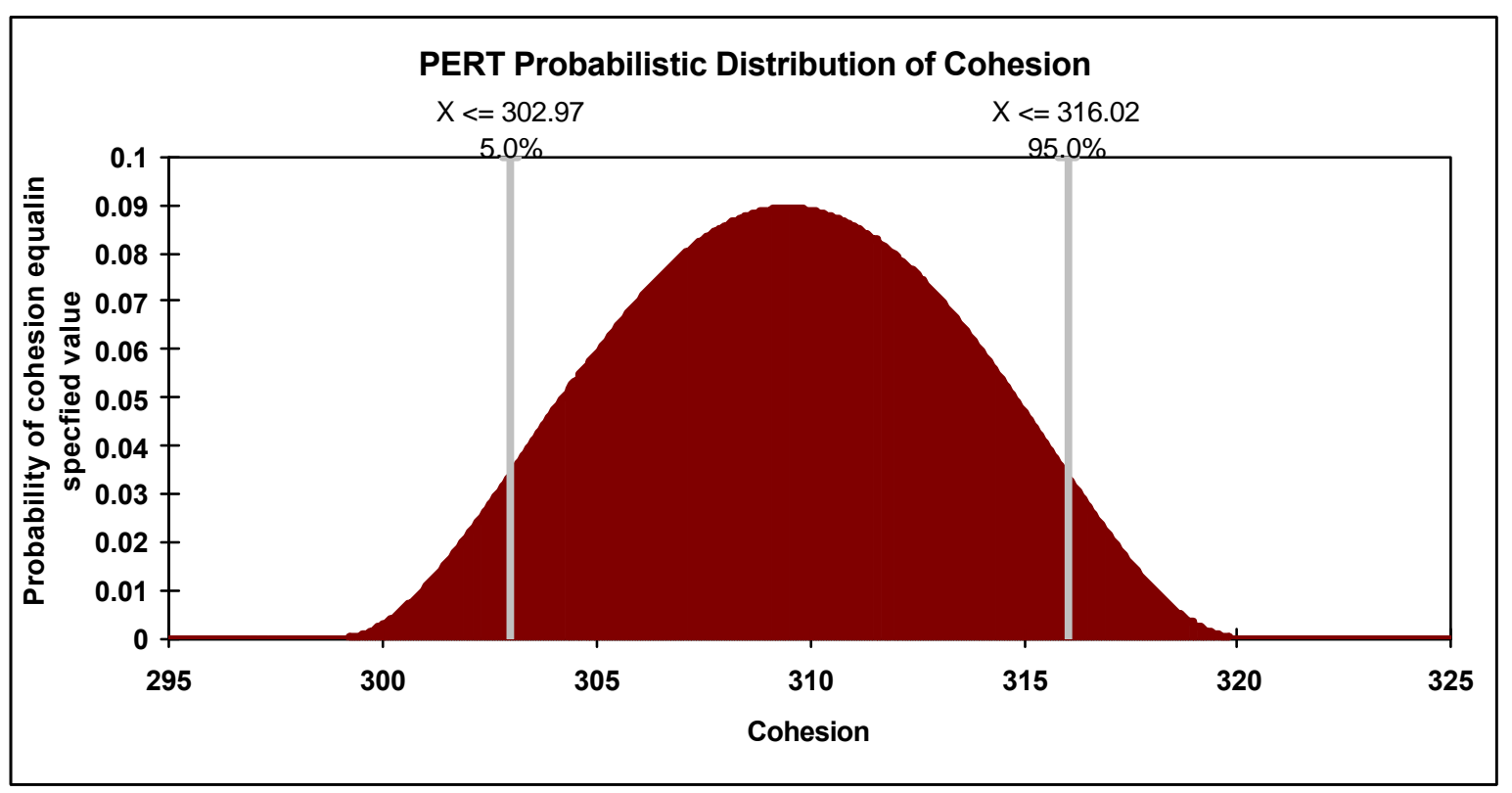

Figure 4-12: PERT distribution of input parameter Cohesion ( c ).

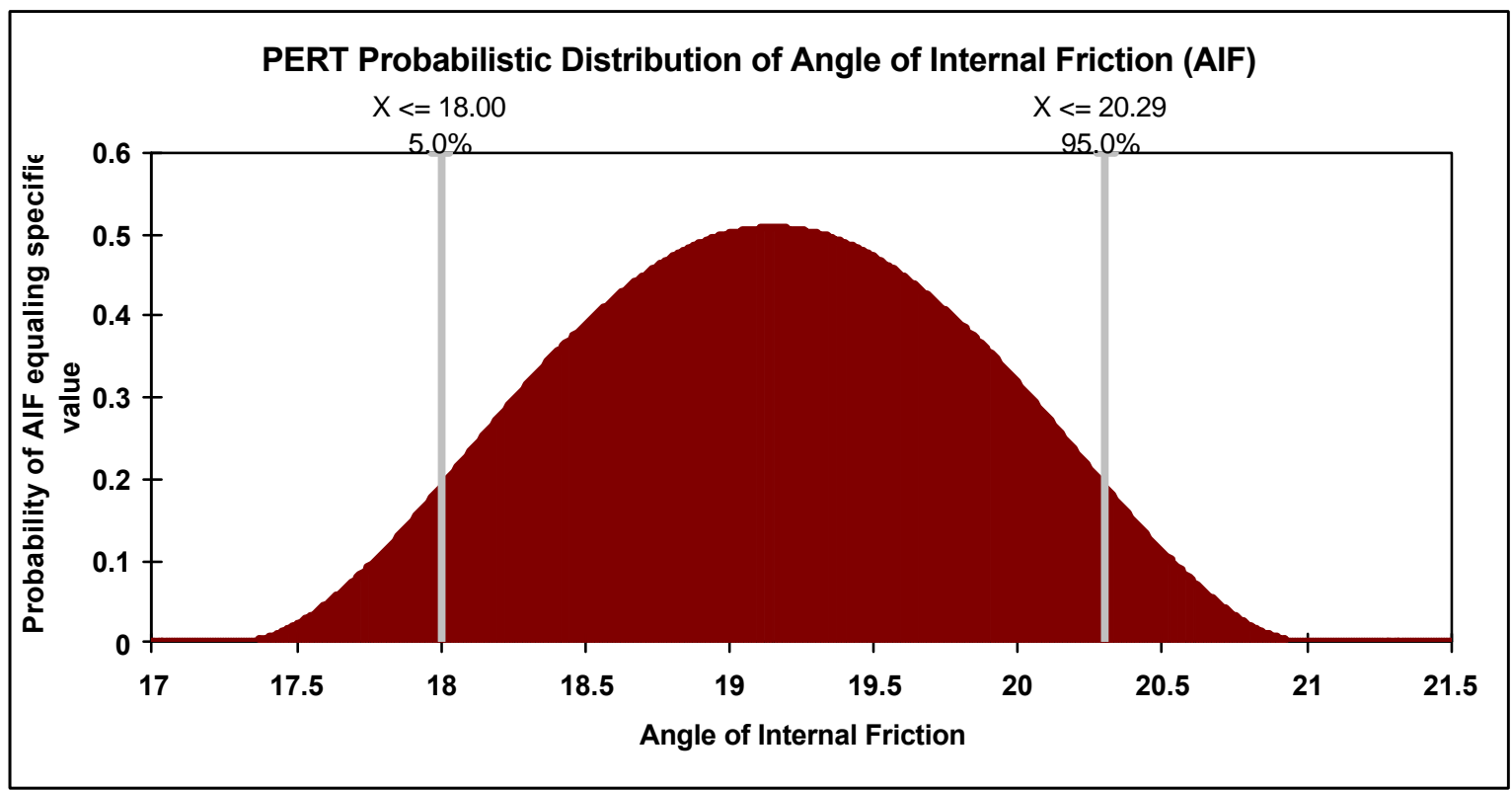

Figure 4-13: PERT distribution of input parameter Angle of Internal Friction $(\phi)$. 
Both the correlation and regression sensitivity analyses indicated the angle of internal friction was the most significant input parameter, followed by cohesion. Figure 4-16 indicates the correlation and regression analysis generated by @RISK for the valley fill slope at site 2 .

The Monte Carlo simulation using the response surface method computed the mean factor of safety as 1.709 , and the standard deviation as 0.05 for the input parameters. These statistical parameters indicate the factor of safety is equal to or greater than 1.62 for $95 \%$ of the combinations of input parameters. Clearly any risk consideration of this slope would identify this as an acceptable situation.

The graduating equation developed using the response surface method, considered only two variables, angle of internal friction $(\phi)$, and cohesion ( c ). For slopes, with multiple sub-surface layers with different geo-mechanical properties, accounting for the variance of each parameter in every layer becomes a tedious exercise. Bishop method of slices works for slopes with more than one sub-surface layers, by taking into consideration the average values of the input parameters for a particular slice. Response surface method does not work in such situations. 


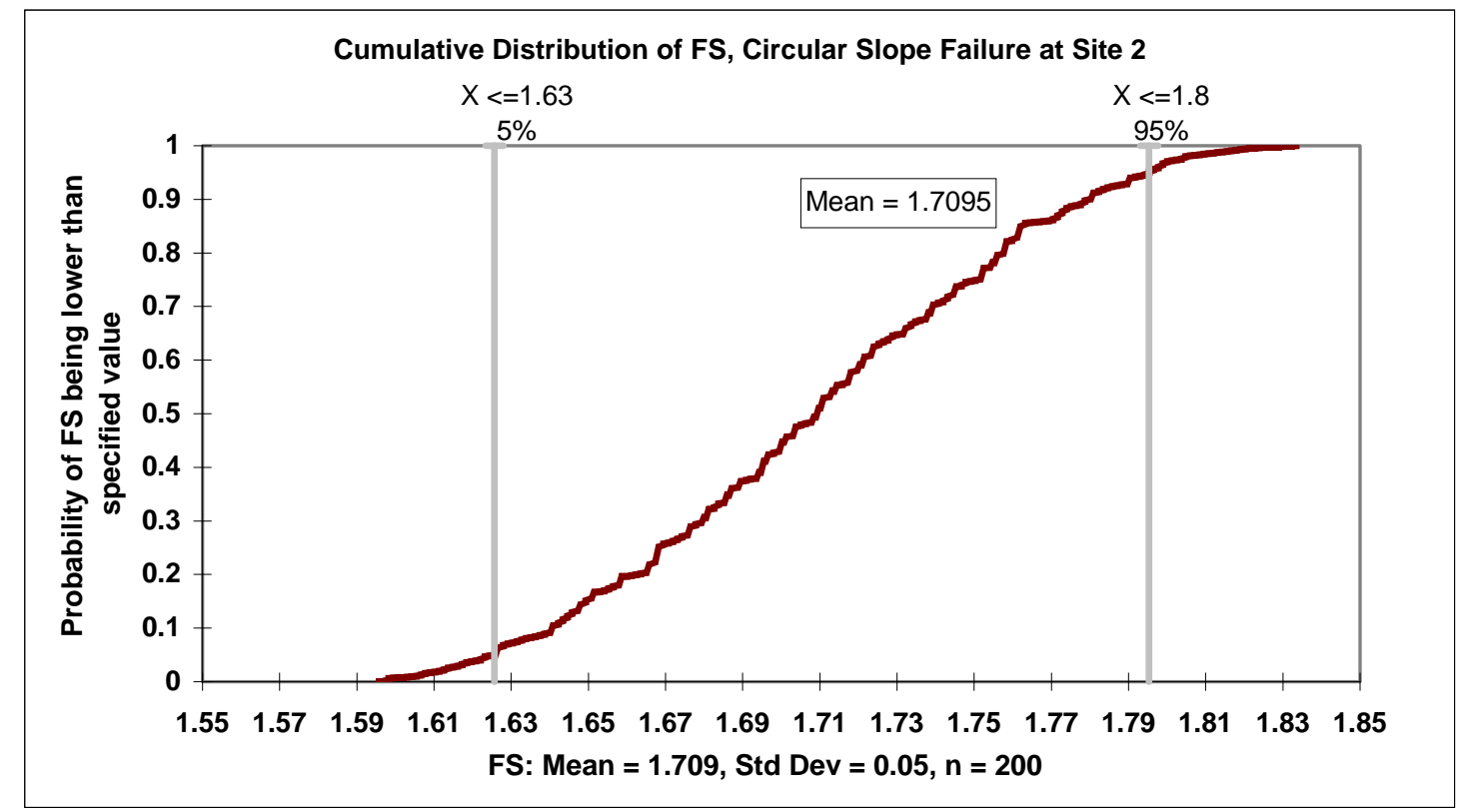

Figure 4-14: Cumulative distribution of FS, Circular Failure Surface at Site $2(n=200)$.

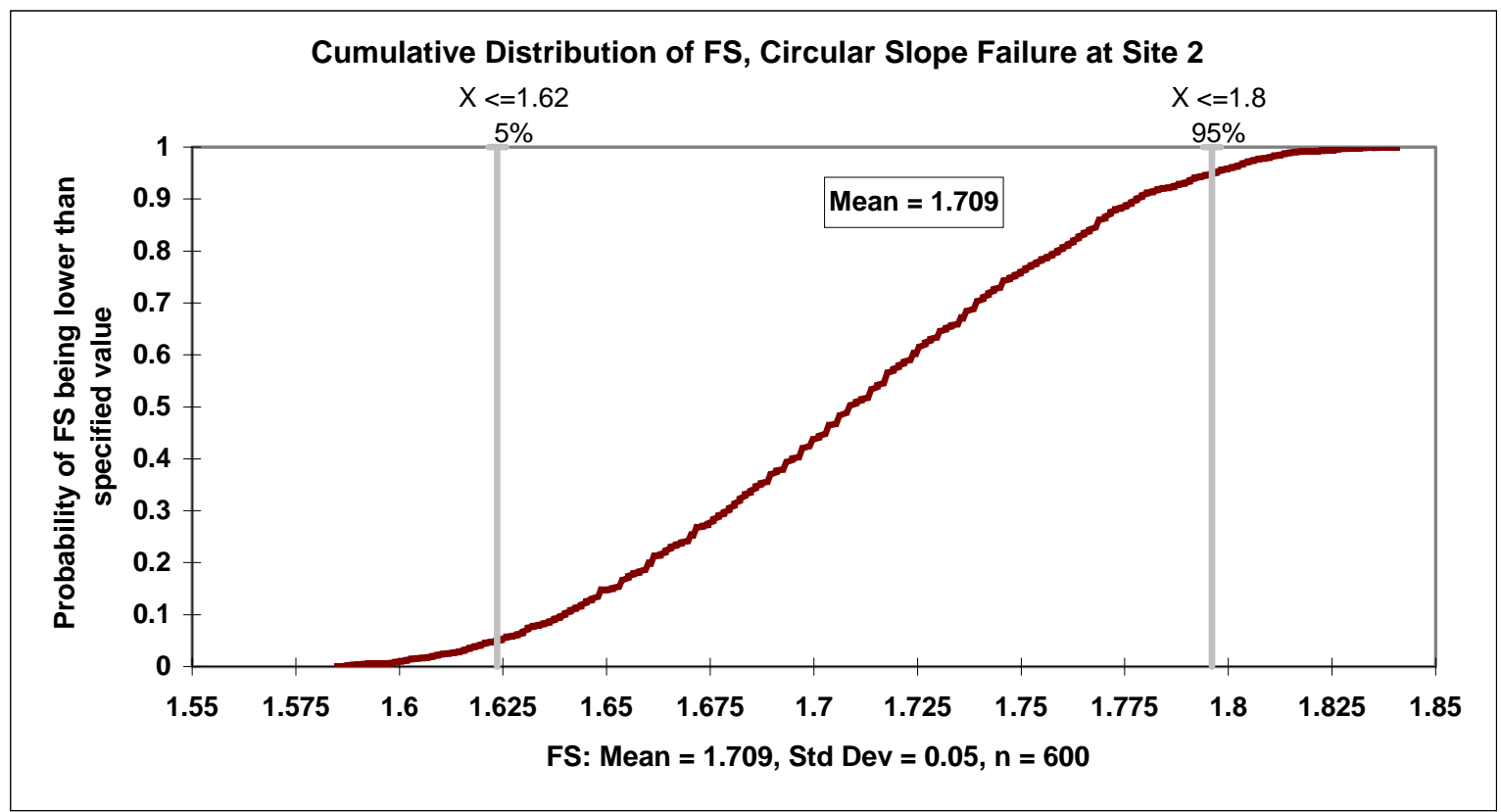

Figure 4-15: Cumulative distribution of FS, Circular Failure Surface at Site $2(n=600)$. 


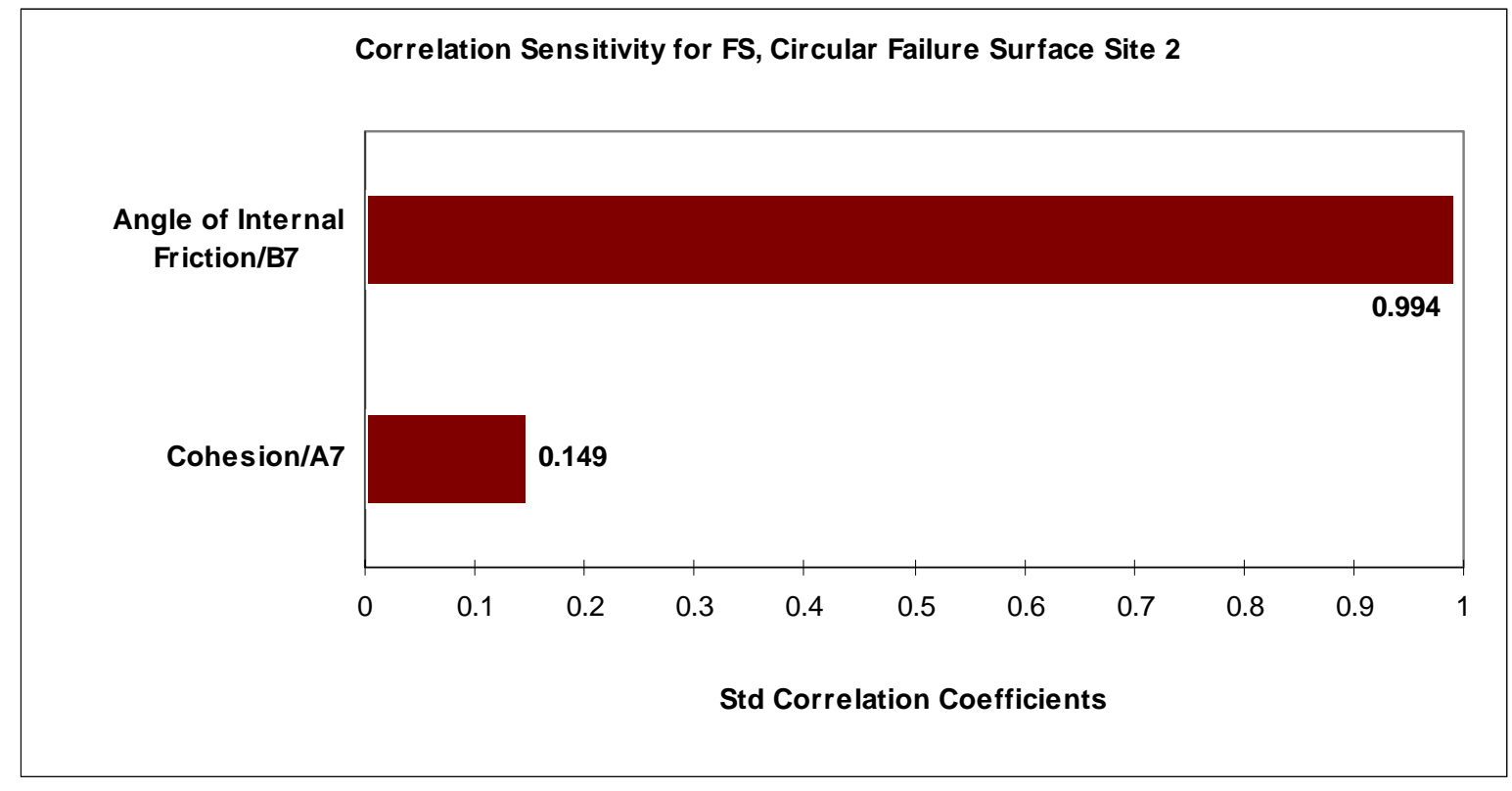

(a) Correlation Sensitivity Analysis

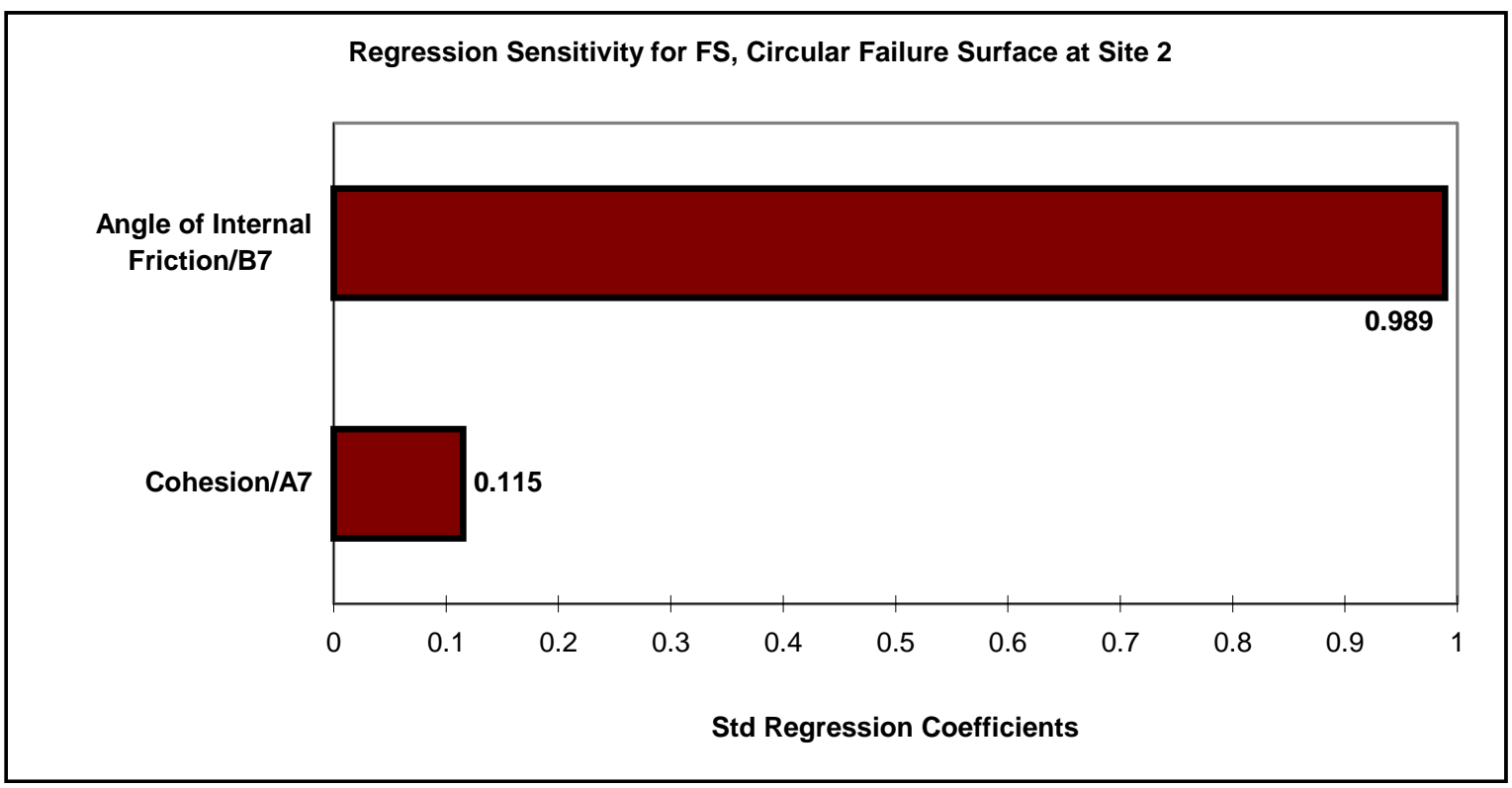

(b) Regression Sensitivity Analysis

Figure 4-16: Sensitivity Analysis for Uncorrelated Input Parameters and FS 


\subsection{Results.}

1. The valley fill at site 1 is an excellent example of a long-standing slope. The Bishop's factor of safety of the slope is 1.26 . This slope is potentially stable due to its configuration.

2. The valley fill at site 2 is a pure spoil slope, with no under cover of natural soil over the lower competent layer of sand stone. The Bishop's factor of safety (FS) of the slope is 1.774. Probabilistic analysis show that 90.0 percent of FS values for this valley fill slope fall in the range of 1.62 to 1.8 . This slope is stable.

3. The valley fill at site 3 has very low relief and great stretch. The spoil volume exceeds 250,000 cubic yard. Bishop's factor of safety of the slope is 2.92, and Janbu's factor of safety of the slope is 2.96. This slope is stable due to its configuration.

The results of the valley fill analysis at Site 1, 2, and 3 are shown in Table 4-5. 
Table 4-5: Summary of valley fill slope stability analysis at Site 1, 2, and 3.

\begin{tabular}{|l|l|l|c|c|c|c|}
\hline Valley fill location & Prominent feature & Special conditions & Deterministic analysis & \multicolumn{2}{|c|}{ Probabilistic analysis } \\
\hline & & & Bishop's FS & Janbu's FS & Mean FS & $\mathbf{9 0 \%}$ FS range \\
\hline Site 1. & Long standing fill slope & $\begin{array}{l}\text { Highly vegetated, all } \\
\text { highwalls were eliminated. }\end{array}$ & 1.26 & 0.28 & NA & NA \\
\hline Site 2. & $\begin{array}{l}\text { Highly vegetated, surface } \\
\text { configuration comply with } \\
\text { the regulations }\end{array}$ & 1.774 & 1.8 & 1.709 & $1.62-1.8$ \\
\hline Site 3. & Pure Spoil fill slope & $\begin{array}{l}\text { High volume of spoil was } \\
\text { disposed }\end{array}$ & 2.92 & 2.97 & NA & NA \\
\hline
\end{tabular}

* FS: Factor of safety. 


\section{Chapter 5}

\section{Summary, and Conclusions}

\subsection{Summary}

Analyzing mining operations laden with uncertain input parameters is a difficult exercise. Coal extraction techniques used in mountaintop projects are some of the wellplanned and executed methodologies used in the world today.

Analysis has shown that valley fill slopes are stable. Inherent variability in soil parameters can be accounted using probabilistic analysis with Monte Carlo Simulation. The gross as well as the local stability of the valley fill slopes were analyzed. The analysis presented herein used a risk based slope analysis method using Monte Carlo Simulation. The response surface method is used to interface the Bishop's method of slices, with the Monte Carlo Simulation.

\subsection{Conclusions}

Based on the results obtained from the studies on coal extraction techniques, and spoil handling techniques, mountaintop mining projects are using the state-of-the-art technology in surface mining. Mining engineers give highest priority to reclamation and restoration, and the reclamation plan is developed and continuously revised to achieve the pre-set post-mine land use.

The valley fill slopes in a number of studied cases from West Virginia, are stable due to configuration. The enormous weight of the spoil placed over the incompetent natural soil tends to consolidate over its own weight. The sliding of the incompetent subsurface layers was not noticed. In the analysis of valley fill spoil slopes; in addition to the deterministic analysis of slope stability, probabilistic approach is also used. It is generally accepted that soil parameters have a normal distribution. However, when the Monte Carlo simulation was performed for an infinite slope, untenable results were obtained due to sampling from the trails of the distribution. To resolve this conflict, the input data were assumed to have a PERT distribution. Simulations using the PERT 
distribution produced reasonable results. It was concluded from the results that the PERT distribution better describes soil parameters, than the normal distribution, particularly when the range of the data is constrained by physical limitations.

From the sensitivity analysis performed for each case study, the unit weight of the soil was found to be the least significant input parameter for determining the stability of a slope for factor of safety analysis. Cohesion and the angle of internal friction were found to be the most significant input parameters for the slopes modeled. Therefore, determining the exact unit weight distribution of soil for a probabilistic analysis of valley fill overburden slopes is less critical than cohesion and the angel of internal friction.

\subsection{Recommendations}

The analysis demonstrated the ability of the mountaintop coal extraction techniques in extracting coal in an environmentally friendly manner. If the AOC conditions or the AOC variance conditions are well understood, and the mines adhere to the governing regulations, mountaintop mining operations will be environment friendly.

However, further analysis is required to be carried out to streamline mountaintop mining operations with the stringent environmental laws, as well as with the economic feasibility limits.

1. Data collection of valley fill overburden spoil slope's input parameters need to be amplified to obtain sufficient information to quantify the distribution of slope parameters and slope geometry.

2. The affect of surface infiltration, run off, and ground vibrations due to blasting on mass wasting in the valley fills are to be studies.

3. The need to develop overburden slope stability analysis software is to be realized. Soil slope stability analysis software provide fair analysis of overburden spoil slopes, but the effect of void spaces, highly diverse grain size distribution, non uniform properties are to be considered for better analysis of spoil slopes. 
4. The Response Surface Method (RSM) criterion was drawn from a single research project. The analysis of valley fill overburden slopes can be used to further validate the methodology. 


\section{References}

1. Office of Surface Mining. (1998). West Virginia Oversight Report: U.S. Department of Interior, Charleston Field Office.

2. White, M. A. \& Barata, F. A., (1995). State-of-the -art in mountaintop removal and contour mining, Mining Engineering: pp. 1111-1114.

3. Transportation Research Bureau (TRB). Landslides: Investigation and Mitigation. (1996). Special report 247. Washington D.C: National Academy Press.

4. Office of Surface Mining. (1999). An Evaluation of Approximate Original Contour and Postmining Land Use in West Virginia, West Virginia Oversight Report: U.S. Department of Interior, Charleston Field Office.

5. Kenny. T. C., (1971). Stability of slopes in overburden excavations, Geotechnical Practice for Stability in Open Pit Mines: pp. 87-105.

6. Das. B., (1994). Principles of Geotechnical Engineering. Boston: PWS Publishing Company, third edition.

7. Hoek, E. \& Bray, J., (1974). Rock Slope Engineering. London: Institute of Mining and Metallurgy, London.

8. Industrial Environmental Research Laboratory. (1981). Environmental Assessment of Surface Mining: Head-of-Hallow Fill and Mountaintop Removal - Draft Final Report: Cincinnati, U. S. Environmental Protection Agency.

9. Perloff, W.H \& Baron, W., (1976). Soil Mechanics: Principles and Applications. New York: Ronald Press Co.

10. Torries. T. F., (1998). Evaluating Mineral Projects: Applications and Misconceptions. SME.

11. @ RISK Manual. (1997). Newfield, NY: Palisade Corporation.

12. Hunt, R., (1984). Geotechnical Engineering Investigation Manual. New York: McGraw-Hill Book Company.

13. Hutchinson, S. \& Bandalos, D., (1997). A Guide to Monte Carlo Simulation Research for Applied Researchers. Journal of Vocational Education Research, Vol.22, pp. 233-245. 
14. Wong, F. (1984). Slope Reliability and Response Surface Method. Journal of Geotechnical Engineering, Vol. 111, pp. 32-53.

15. Petterson, J. L., (1999). Probabilistic Analysis of Slope Stability. WVU: Masters Thesis. 